\title{
Towards a Utility Theory of Privacy and Information Sharing and the Introduction of Hyper-Hyperbolic Discounting in the Digital Big Data Age
}

\author{
Julia M. Puaschunder \\ The New School, Department of Economics, \\ Schwartz Center for Economic Policy Analysis, NY, USA \\ Julia.Puaschunder@newschool.edu,http://juliampuaschunder.com/ \\ Columbia University, Graduate School of Arts and Sciences, USA \\ Julia.Puaschunder@columbia.edu \\ Princeton University, Julia.Puaschunder@princeton.edu
}

\begin{abstract}
Economics is concerned about utility. Utility theory captures people's preferences or values. As one of the foundations of economic theory, the wealth of information and theories on utility lacks information about decision-making conflicts between preferences and values. The preference for communication is inherent in human beings as a distinct feature of humanity. Leaving a written legacy that can inform many generations to come is a humaneunique advancement of society. At the same time, however, privacy is a core human value. People choose what information to share with whom and like to protect some parts of their selves by secrecy. Protecting people's privacy is a codified virtue around the globe grounded in the wish to uphold individual's dignity. Yet to this day, no utility theory exists to describe the internal conflict arising from the individual preference to communicate and the value of privacy. In the age of instant communication and social media big data storage and computational power; the need for understanding people's trade off between communication and privacy has leveraged to unprecedented momentum. For one, enormous data storage capacities and computational power in the e-big data era have created unforeseen opportunities for big data hoarding corporations to reap hidden benefits from individual's information sharing, which occurs bit by bit in small tranches over time. Behavioral economics describes human decision making fallibility over time but has - to this day - not covered the problem of individuals' decision to share information about themselves in tranches on social media and big data administrators being able to reap a benefit from putting data together over time and reflecting the individual's information in relation to big data of others. The decision making fallibility inherent in individuals having problems understanding the impact of their current information sharing in the future is introduced as hyper-hyperbolic discounting behavioral economics decision making predicament. While behavioral economics
\end{abstract}


hyperbolic discounting theory introduces the idea of time-inconsistency of preferences between an individual now and the same individual in the future; hyper-hyperbolic discounting underlines that in the case of information sharing versus secrecy preferences this fallibility is exacerbated to a larger extent. Individuals lose control over their data without knowing what surplus big data moguls can reap from the social media consumer-workers' information sharing, what information can be complied over time and what information this data can provide in relation to the general public's data in drawing inferences about the innocent individual information sharer. For instance, big data derived personality cues have recently been used for governance control purposes, such as in border protection and tax compliance surveillance. The utility theory of contradicting information sharing and privacy predicaments is presented in this paper for the first time and a nomenclature of different personality types regarding information sharing and privacy preferences is theoretically introduced. Unravelling the utility of information sharing versus privacy conflict holds economic theory advancement and governance improvement potentials in the digital age. The presented piece can also serve as a first step towards advocating for education about information sharing in order to curb harmful information sharing discounting fallibility. From legal and governance perspectives, the outlined ideas may stimulate the e-privacy infringement regulations discourse in the pursuit of the greater goals of democratisation of information, equality of communication surplus and upheld humane dignity and e-ethics in the big data era.

Key words: Behavioral Economics, Behavioral Political Economy, Democratisation of information, Education, Exchange value, Governance, Preferences, Right to delete, Right to be forgotten, Social media, Utility, Value

\section{Introduction}

Utility theory is concerned with people's choices and decisions based on preferences and values (Fishburn, 1968). Representing satisfaction experienced, utility is derived from the self-attributed worth and goodness of an option compared to other options. Standard neo-classical economic theory describes utility as a set of internallyconsistent assumptions about options in the wish to maximize utility (Fishburn, 1968). Utility theory has leveraged as one of the most dominant theories in economics as an underpinning of rational choice and game theory. Utility is usually revealed in people's willingness to pay different money amounts for different options, leading to the concept of revealed preferences (Samuelson, 1937).

Whereas economic utility studies primarily focus on prescriptive approaches to guide how people should behave to maximize their well-being (Arrow, 1951, 1958; Majumdar, 1958; Simon, 1959); decision sciences started capturing how people actually decide regarding choices in an uncertain world and over time (Becker \& McClintock, 1967; Edwards, 1954, 1961; Luce \& Suppes, 1965). Expected utility theory introduces a first temporal discussion of expectations of utility rather than the actual utility derived from a choice (Alchian, 1953; Marschak, 1950; Strotz, 1953). 
Von Neumann and Morgenstern (1953) presented first that outcomes of choices are not known with certainty but have probabilities of occurrence, whose weighted linear combination allows inferences about the overall utility derived over time.

Since the end of the 1970ies, a wide range of psychological, economic and sociological laboratory and field experiments proved human beings deviating from rational choices as standard neo-classical profit maximization axioms to fail to explain how human actually behave (Kahneman \& Thaler, 1991). Human beings were shown to use heuristics in the day-to-day decision making as mental short cuts that enable to cope with information overload in a complex world (Bazerman \& Tenbrunsel, 2011; Kahneman \& Tversky, 1979; Thaler \& Sunstein, 2008).

As one of the most recent developments in utility theory studies, behavioral economics find human utility choices biased (Bowles, 2004; Camerer, Loewenstein \& Rabin, 2004; Ebert \& Prelec, 2007; Kahneman, 2011; Okada \& Hoch, 2004; Putnam, 2002; Sen, 1971, 1993, 1997, 2002a; Zauberman, Kim, Malkoc \& Bettman, 2009) by heuristics (Kahneman, Slovic \& Tversky, 1982; Simon, 1979), analogical thinking (Colinsky, 1996; Gentner, 2002), and minimized effort (Allport, 1979; Shah \& Oppenheimer, 2008).

In particular, people's cognitive capacities to consider future outcomes in today's decisions are limited (Doyle, 2013; Laibson, 1997; Loewenstein, 1992; Milkman, Rogers \& Bazerman, 2009; Read, Loewenstein \& Kalyanaraman, 1999; Read \& van Leeuwen, 1998). Laibson's (1997) hyperbolically decreasing discounting functions more accurately describe choice behaviors of individuals, who tend to be impatient for smaller rewards now rather than waiting for larger ones later (e.g., Ainslie, 1992; Becker \& Murphy, 1988; Doyle, 2013; Estle, Green, Myerson \& Holt, 2007; Frederick, Loewenstein \& O’Donoghue, 2002; Green, Fry \& Myerson, 1994; Green \& Myerson, 2004; Hansen, 2006; Henderson \& Bateman, 1995; Kirby, 1997; Kirby \& Marakovic, 1995; Laibson, 1997; Loewenstein \& Prelec, 1993; Mazur, 1987; Meyer, 2013; Murphy, Vuchinich \& Simpson, 2001; Myerson \& Green, 1995; Rachlin, Raineri \& Cross, 1991; Sterner, 1994). Dynamically inconsistent preferences reverse as people are patient when deciding for the future and impatient when choosing for now (Hornsby, 2007; Laibson, 1997; McClure, Ericson, Laibson, Loewenstein \& Cohen, 2007; Meyer, 2013; Reed \& Martens, 2011; Thaler, 1981).

Field and laboratory experiments provide widespread empirical evidence for hyperbolic discounting and self-control failures (Frederick et al., 2002; Hoch \& Loewenstein, 1991; Sen, 1971, 2002b) on money management (Alberini \& Chiabai, 2007; Chabris, Laibson \& Schuldt, 2008; Coller \& Williams, 1999; Harrison, Lau \& Williams, 2002; Keller \& Strazzera, 2002; Kirby \& Marakovic, 1995; Laibson, 1997; Laibson, Repetto \& Tobacman, 2003; Salanié \& Treich, 2005; Slonim, Carlson \& Bettinger, 2007; Thaler \& Shefrin, 1981; Warner \& Pleeter, 2007), financial benefits (Cairns \& van der Pol, 2008), credit card debt (Meier \& Sprenger, 2010; Shui \& Ausubel, 2004), medical adherence (Trope \& Fishbach, 2000), public health (Bosworth, Cameron \& DeShazo, 2006; Cameron \& Gerdes, 2003; Chapman, 1996a; 
Duflo, Banerjee, Glennerster \& Kothari, 2010; Horowitz \& Carson, 1990; van der Pol \& Cairns, 2001), addiction (Badger, Bickel, Giordano, Jacobs, Loewenstein \& Marsch, 2007; Becker \& Murphy, 1988; Heyman, 1996; Laux \& Peck, 2007; Madden, Bickel \& Jacobs, 1999; Petry \& Casarella, 1999), social security (Mastrobuoni \& Weinberg, 2009), fiscal policies (Keeler \& Cretin, 1983), commitment (Duflo, Kremer \& Robinson, 2008; Sen, 1977, 2002b), health exercise (DellaVigna \& Malmendier, 2004, 2006), employment (DellaVigna \& Paserman, 2005), procrastination (Reuben, Sapienza \& Zingales, 2010), diet (Read \& van Leeuwen, 1998), subscription discipline (Oster \& Scott-Morton, 2005), animal care (Green, Fry \& Myerson, 1994; Mazur, 1987), and consumption (Milkman, Rogers \& Bazerman, 2008; Read et al., 1999; Wertenbroch, 1998). Failures to disciplinedly stick to plans for giving in to immediate desires (Ainslie \& Haslam, 1992; Read, Frederick \& Airoldi, 2012; Strotz, 1956) are explained by people caring less about future outcomes in the eye of future uncertainty (Luce \& Raiffa, 1957; Shackle, 1955), perceived risk (Mas-Colell, Whinston \& Green, 1995), and transaction costs (Chung \& Herrnstein, 1967; Epper, Fehr-Duda \& Bruhin, 2011; Frederick et al., 2002; Kirby \& Herrnstein, 1995; Mazur, 1987; Read, 2001). Presenting temporal snapshots for now and later concurrently helps overcome myopia and decision making fallibility (Puaschunder \& Schwarz, 2012). In all these studies missing is an investigation of human decision making on preferences for information sharing in communication and privacy in secrecy.

Although communication and non-communication are day-to-day decisions of individuals, to this day, there is no stringently-tested utility theory of information sharing and privacy. We lack a coherent decision science framework about when people choose to share information and when they rather want to stay silent for the sake of privacy. From the economic perspective, information sharing may impose temporal irreversible lock-ins or tipping points. The point of information sharing may be a reference point, in which one bit of more communication gives less utility than one bit of less information shared, hence one bit of more privacy, grants more utility in the sense of Kahneman \& Tversky's (1979) behavioral decision science finding 'losses loom larger than gains.' There may also be a marginal decreasing utility derived from one bit more information shared but an exponential marginal utility gain from one more unit of information received given the fact that information can be put into context. Education, for instance, is often said as the only good with an exponential marginal utility increase, as the more information one holds, the more complex connections one can make and use.

In the digital age, the study the trade off between information sharing and privacy has leveraged into unprecedented importance in the digital social media era. Social media revolutionized human communication around the globe. As never before in the history of humankind, information about individuals can be stored and put in context over time and logically placed within society thanks to unprecedented data storage and computational powers. The big data era, however, also opened gates to 
unprecedentedly reap benefits from information sharing and big data generation (Puaschunder, 2017). The so-called nudgital society was recently introduced, shedding a light onto the undescribed hidden social class division into social media users and social media providers, who can benefit from the information shared by social media users. Social media users share private information in their wish to interact with friends and communicate to public. The social media big data holder can then reap surplus value from the information shared by selling it to marketers, who can draw inferences about consumer choices. The big data can also be used for governance control purposes, for instance border protection and tax compliance control.

Drawing from the economic foundations of utility theory, this paper seeks the introduce the first application of utility theory to a preference-values predicament between communication and privacy in the new media era. Behavioral economics insights are advanced in shedding novel light on the conflict between the humane wish to communicate now versus combined information held by unknown big data compilers in the future. An exponential loss of privacy and hyper-hyperbolic risks in the future for the information sharer are introduced as behavioral economic decision making fallibilities. For the information sharer it remains largely unforeseeable what the sum of the individual information sharing tranches can lead to over time and what information its Gestalt holds for those who hold big data insights over time, which can also be analyzed in relation to the general population. Governance gains a critical stance on new media use for guiding on public concerns regarding privacy and information sharing in the digital age (Puaschunder, 2017).

The article is structured as follows: An introduction of the theory of utility and communication and information sharing is followed by an outline of the impetus of the digital big data age on privacy. The first utility theory of information sharing and privacy will be theoretically introduced. Hyperbolic decision making fallibility will become the basis of argumentations around hyper-hyperbolic discounting - the novel argument that information sharing in tranches may lead to an underestimation of the privacy infringements when these bits of information can be put together over time and are compared to big data driven population inferences. The subjective additive utility of information shared tranche by tranche may underestimate the big data holder's advantage to reap benefits from information shared. The discussion introduces problems of the contemporary nudgital society (Puaschunder, 2017), in which big data compilers can reap a surplus value from selling compiled information (The New York Times, November 14, 2017) ${ }^{1}$ or manipulate vulnerable population segments based on their previously shared information (The Economist, November 4, 2017). ${ }^{2}$ Implications lead to open questions about ethics in the information age and recommendations for education about information sharing in the digital age as well as

1 https://www.nytimes.com/2017/11/14/business/dealbook/taxing-companies-for-using-our-personaldata.html?rref $=$ collection $\% 2$ Fsectioncollection $\% 2$ Fbusiness\&action=click\&contentCollection=busines s\&region=stream\&module $=$ stream_unit\&version=latest\&contentPlacement $=8 \&$ pgtype $=$ sectionfront

2 https://www.economist.com/news/leaders/21730871-facebook-google-and-twitter-were-supposedsave-politics-good-information-drove-out 
the democratization of information in the $21^{\text {st }}$ century big data social media era. Challenging contemporary behavioral insights theory aims at fostering a more selfinformed and protected digital society in the wish to uphold e-ethics.

\section{Theory}

\subsection{Utility theory}

Economic theory is built upon the idea of utility, which captures people's preferences or values (Fishburn, 1968). Human are believed to strive to maximize utility on a constant basis by weighting their preferences and values on the pleasure they would receive from different options. In neoclassic economics, utility theory primarily focuses on prescriptive utility maximization giving recommendations how individuals should behave to maximize their utility. Prescriptive utility maximization theory serves as normative guide in helping the decision maker codify preferences. If preferences would violate rational preference choices, the theory suggests strategies so the informed decision maker can revise their rational reference choices and judgments to eliminate preference inconsistency. Using utility theory, preferences are constantly transformed into corresponding numerical utility data that maximizes the individual's pursuit of happiness. Utility theory provides a powerful set to determine how to compare actual alternatives. It enables the decision maker's optimal preferences to be transformed into a numerical utility structure guided by an optimization algorithm.

In doing so, standard microeconomic utility theory has been of aid to explain how to maximize individual outcomes in very many different domains ranging from marketing research (Greenberg \& Collins, 1966; Marquardt, Makens \& Larzelere, 1965; Stafford, 1966), food industry quality control of products and corporate strategies (Read, 1964; Stillson, 1954) and production (Aumann \& Kruskal, 1958, 1959; Suzuki, 1957).

\subsubsection{Expected utilities}

Utility maximization lies at the heart of common sense rational decision making. It provides a powerful tool to resolve multidimensional value maximization by weighting the pros and cons of alternatives in additive utility theory. Uncertainty can be coped with by comparing expectations as to what might results from alternative choices in expected utility theory. The so-called stochastic utility theory makes assumptions in terms of probabilities of choice rather than capturing actual preferences (Debreu, 1958, 1960; Fishburn, 1968; Suppes, 1961). Expected utility theory therefore introduces a first temporal discussion of expectations of utility rather than the actual utility derived from a choice later (Alchian, 1953; Marschak, 1950; Strotz, 1953). Given future uncertainty, the utility of any $P$ can be computed as the weighted sum of the utilities of the $\mathrm{x}$ in $\mathrm{X}$, the weights being the probabilities assigned by $P$. The expected utility equation reads (Bernoulli, 1954): 
$u(P)=P\left(x^{1}\right) u\left(x^{1}\right)-P\left(x^{2}\right) u\left(x^{2}\right)+\cdots+P\left(x^{\pi}\right) u\left(x^{n 2}\right)$,

(Equation 2.1)

Whereby $\boldsymbol{u}$ stands for utility, $P$ denotes probability of the $\boldsymbol{u}$ of the separate alternatives $\boldsymbol{x}^{1}$, $x^{2} \ldots x^{\pi}$. The weighting of different alternatives in relation to each other is exhibited in indifference curves (Edgeworth, 1881; Pareto, 1906/2014).

\subsubsection{Indifference curves}

According to utility theory, individuals are constantly evaluating competing choice options. Given a consumer's budget constraints and prices of goods, commodity bundle arise, in which consumers weight alternative options based on their expected utility derived. Indifference curves connect points on a graph representing different quantities of two goods, between which a consumer is indifferent. For instance, if a consumer weights whether or not to buy good $x$ or good $y$, the indifference curves would outline how much of good $x$ and good $y$ can be consumed to end with the same utility given the budget of the consumer. This is how much the utility of one good must be increased to offset a decrease in the utility of another good.

Graph 1 represents standard indifference curves for two competing goods, good $x$ and good $y$. The indifference curve outlines, that the consumer has no preference for one combination or bundle of goods over a different combination of the same curve. All points on the curve hold the same utility for the consumer. The indifference curve is therefore the locus of various points of different combinations of two goods providing equal utility to the consumer. Indifference curves represent observable demand patterns for individual consumers over commodity bundles (Edgeworth, 1881; Pareto, 1906/2014). ${ }^{3}$

In classical economics, an individual is believed to always being able to rank any consumption bundles by order of preference (Jevons, 1871). ${ }^{4}$ The curves are negatively sloped curves - as the quantity consumed of one good $x$ increases, total satisfaction increases if not offset by a decrease in the quantity of good $y$. Indifference curves fulfill the axioms of completeness, transitivity and strictly convex preferences. Preferences are complete, meaning the consumer ranks all available alternative combinations of commodities in terms of satisfaction provided. Preference rankings are reflexive, transitive, continuous and strongly monotonous. There is a strongly holding substitution assumption, meaning that consumers are believed to willingly give up or trade-off some of one good to get more of another. The fundamental assertion is that there is a maximum amount that a consumer is willing to give up of one commodity to get another commodity, which will leave the consumer indifferent between the new and the old situation (Silberberg, 2000).

\footnotetext{
3 https://archive.org/details/mathematicalpsy01goog

4 http://www.econlib.org/library/YPDBooks/Jevons/jvnPE.html
} 
Indifference curves are determined by the prices of goods and budget constraints of consumers. Indifference curves for substitute goods are straight lines - see the straight line in green in graph 2 representing a budget constraint for substitute goods.

Graph 1: Indifference curve (blue curve) for two goods, good $x$ and good $y$ given their budget constraint (red line)

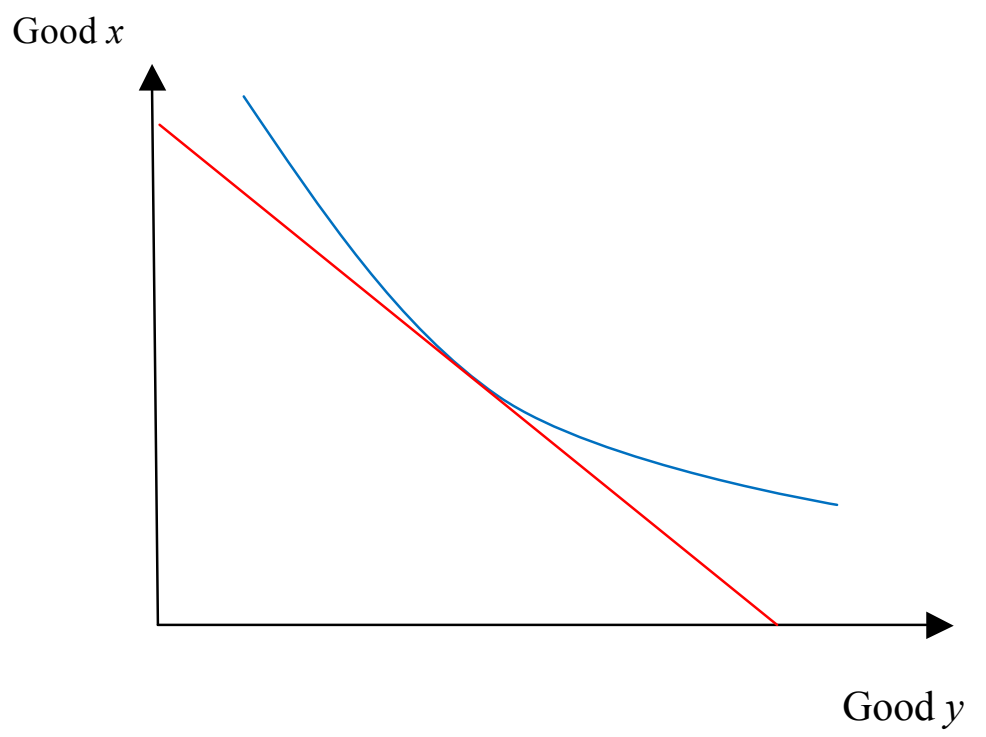

Graph 2: Indifference curve (green line) for substitute goods, good $x$ and good $y$

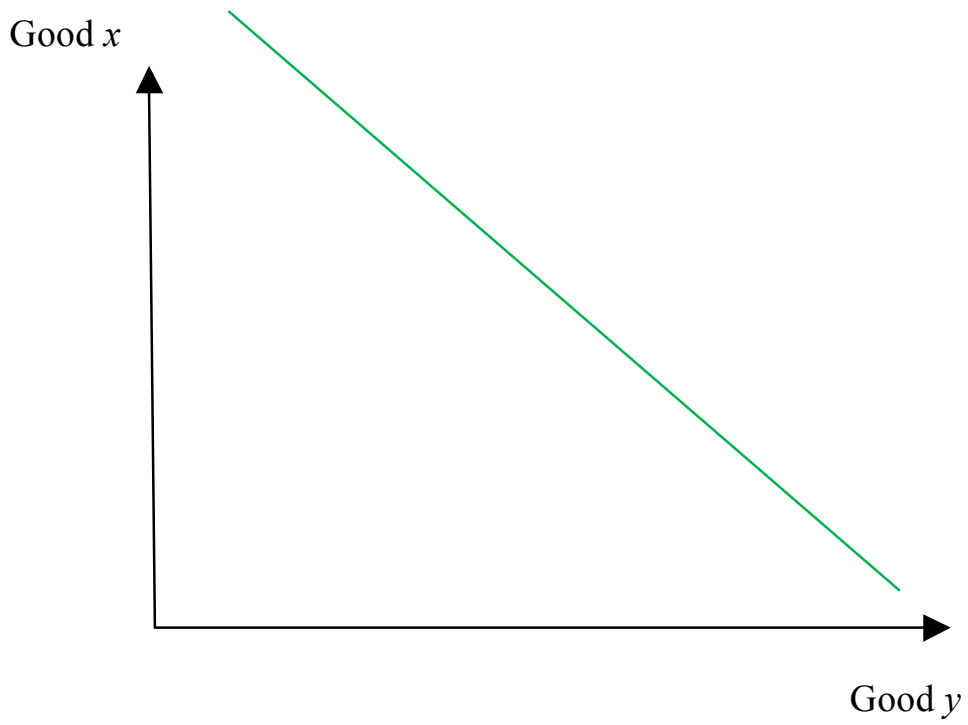

The slope of an indifference curve in absolute value is the marginal rate of substitution, which explains the rate at which consumers are willing to give up one good in exchange for more of the other good. For most goods the marginal rate of substitution is not constant so their indifference curves are curved. 


\subsubsection{Time preferences}

When making decisions, people may contemplate a sequence of choices - some with outcomes now and some with outcomes later. The so-called hyperbolic conundrum lies in the present utility often turning into future disutility. Building on standard neoclassical utility theory offering a first nomenclature of time preferences among the population, standard utility theory (Fishburn, 1968) therefore categorized types of decision makers over time into:

(1) extreme impatience: only immediate pleasures are valued, people are overwhelmingly concerned with immediate pleasures;

(2) impatience: discounting the future, e.g. featured in work of Diamond, Koopmans and Williamson (1962), Feldstein (1965), Koopmans (1960), Koopmans, Diamonds and Williamson (1964), Marglin (1963), and Strotz (1957);

(3) eventual impatience: discounting may not occur in the present and the near future, but all periods sufficiently far away will be discounted at some point in the future, for instance discussed in Diamond (1965);

(4) time perspective: related to hyperbolic-discounting as in Koopmans et al. (1964) and Laibson (1997);

(5) no time preference: at the present time, the individual neither discounts nor overcounts the future with respect to the present - find this idea in the work of Diamond (1965), Fishburn (1966), Ramsey (1928), Wold (1952);

(6) persistence: stationarity of a consistent preference structure in Diamond (1965), Koopmans (1960), Koopmans et al. (1964); and

(7) variety: or nonpersistence as consistently varying preference structure as described in Wold (1952).

Overall, all these notions apply to preferences concerning the future, viewed from the present given general uncertainty about what our preferences for future events will be in the future. This nomenclature addresses the problem of capturing valid preference structures over time that allow stringent predictions of choice behavior and strategies for future planning (Fishburn, 1968).

While standard neoclassical economic theory defines utility to be about preferences and values maximization, no theory framework for the predicament between preferences and values exists to date, which may be theoretically grounded in the critical extension of neoclassical economics.

On a large scale, utility theory provides inferences about behavioral tendencies of individuals to predict the reaction of a social group to changes in commodity prices and incomes. Economists are enabled to evaluate changes of income and prices for consumers following the greater goal of improving the social good on the basis of utility predictions. Governance can derive recommendations for prescribing economic policies that will be overall most beneficial to a society. Welfare economics is a powerful example of the prescriptive use of utility theory in practice (Debreu, 1964; Rothenberg, 1961). 


\subsection{Behavioral economics}

While the theory has its clear merits and noble endeavors to aid decision makers to discover how to determine the optimal preference structure in a complex world; behavioral economics found individuals having difficulties to make preference comparisons on a constant basis in a complex, multidimensional world of uncertainty.

Starting with psychological studies in the wish to derive a predictive ability of utility preference choices and choice behavior, behavioral economics (Simon, 1993) revolutionized economic theory by finding human decision making persistently deviating from rational choice axioms (Sen, 1971, 1993, 1997, 2002a). Whereas economic utility studies primarily focus on prescriptive approaches to guide how people should behave to maximize their well-being (Arrow, 1951, 1958; Majumdar, 1958; Simon, 1959); behavioral economists and decision sciences specialists have rather captured how people actually decide on choices (Becker \& McClintock, 1967; Edwards, 1954, 1961; Luce \& Suppes, 1965). Behavioral economics offers an alternative description how individual actually choose to pursuit their utility maximization in more intuitive decision approaches. Predictive utility and behavioral economics thereby followed the wish to aid decision maker cope with a complex world and discover his or her preference architecture in a set of alternatives under uncertainty.

Behavioral economists finds human time perception biased (Bowles, 2004; Camerer, Loewenstein \& Rabin, 2004; Ebert \& Prelec, 2007; Kahneman, 2011; Okada \& Hoch, 2004; Putnam, 2002; Zauberman, Kim, Malkoc \& Bettman, 2009) by heuristics (Kahneman, Slovic \& Tversky, 1982; Simon, 1979), analogical thinking (Colinsky, 1996; Gentner, 2002), and minimized effort (Allport, 1979; Shah \& Oppenheimer, 2008). An impressive line of research has shown that heuristics lead to predictable and systematic errors (Tversky \& Kahneman, 1974). Individuals are therefore believed to satisficing regarding their options, meaning to break them down in less complex choice sets than the actual alternatives (Simon, 1957).

By studying human decision making fallibility and its consequences, behavioral economics argues that people make decisions based on rules of thumb heuristics that dominate human choices (Gigerenzer, 2014, 2016; Kahneman \& Tversky, 2000). Laboratory experiments have captured heuristics as mental short-cuts easing mentally constrained human in a complex world (Cartwright, 2011; Sen, 1977; Simon \& Bartel, 1986). Mental short cuts were outlined to simplify decision making and substitute difficult questions with easy applicable automatic behavioral reactions (Kahneman, 2011).

Heuristics cause people to make choices much faster, but ultimately less logically than more careful, long-form, decision making. From these insights gained, decision making failures became studied in order to improve human decision making outcomes over time and in groups (Camerer et al., 2004). These cognitive mental shortcuts are most crucial if they set humans on a path to erroneous choices over time. Multi-period decision making addresses that for each time period, another set of 


\section{RAIS COLLECTIVE VOLUME - ECONOMIC SCIENCE}

preferences for the same options can be expected. Decision preference vary over time in the eye of uncertainty.

One of the major problems detected by behavioral economics lies in preferences being dependent on past experiences and present expectations, which are time inconsistent as people's cognitive capacities (Doyle, 2013) to consider future outcomes in today's decisions are limited (Laibson, 1997; Loewenstein, 1992; Milkman, Rogers \& Bazerman, 2009; Read, Loewenstein \& Kalyanaraman, 1999; Read \& van Leeuwen, 1998). In carefully designed repetitive-choice situations, individuals exhibited to have shifting preferences and malleable choices. In laboratory and field experiments, individuals were found to consider alternatives on a constant basis based on many factors and attributes that can span a number of time periods. They have difficulty in arriving at an overall preference between alternatives, especially when weighting some importance factors on one dimension and other importance determinates on another (Fishburn, 1968).

While standard microeconomic theory captures exponential temporal discounting to explain rational decision making; Laibson's (1997) hyperbolically decreasing discounting functions describe more accurately choice behavior of individuals, who tend to be impatient for smaller rewards now rather than waiting for larger ones later (e.g., Ainslie, 1992; Becker \& Murphy, 1988; Doyle, 2013; Estle et al., 2007; Frederick, Loewenstein \& O’Donoghue, 2002; Green, Fry \& Myerson, 1994; Green \& Myerson, 2004; Hansen, 2006; Henderson \& Bateman, 1995; Kirby, 1997; Kirby \& Marakovic, 1995; Laibson, 1997; Loewenstein \& Prelec, 1993; Mazur, 1987; Meyer, 2013; Murphy, Vuchinich \& Simpson, 2001; Myerson \& Green, 1995; Rachlin, Raineri \& Cross, 1991; Sterner, 1994). Dynamically inconsistent preferences reverse as people are patient when deciding for the future and impatient when choosing for now (Hornsby, 2007; Laibson, 1997; McClure, Ericson, Laibson, Loewenstein \& Cohen, 2007; Meyer, 2013; Reed \& Martens, 2011; Thaler, 1981). Field and laboratory experiments provide widespread empirical evidence for hyperbolic discounting and self-control failures (Frederick et al., 2002; Hoch \& Loewenstein, 1991; Sen, 1971, 2002) on money management (Alberini \& Chiabai, 2007; Chabris, Laibson \& Schuldt, 2008; Coller \& Williams, 1999; Harrison, Lau \& Williams, 2002; Keller \& Strazzera, 2002; Kirby \& Marakovic, 1995; Laibson, 1997; Laibson, Repetto \& Tobacman, 2003; Salanié \& Treich, 2005; Slonim, Carlson \& Bettinger, 2007; Thaler \& Shefrin, 1981; Warner \& Pleeter, 2007), financial benefits (Cairns \& van der Pol, 2008), credit card debt (Meier \& Sprenger, 2010; Shui \& Ausubel, 2004), medical adherence (Trope \& Fishbach, 2000), public health (Bosworth, Cameron \& DeShazo, 2006; Cameron \& Gerdes, 2003; Chapman, 1996a; Duflo, Banerjee, Glennerster \& Kothari, 2010; Horowitz \& Carson, 1990; van der Pol \& Cairns, 2001), addiction (Badger, Bickel, Giordano, Jacobs, Loewenstein \& Marsch, 2007; Becker \& Murphy, 1988; Heyman, 1996; Laux \& Peck, 2007; Madden, Bickel \& Jacobs, 1999; Petry \& Casarella, 1999), social security (Mastrobuoni \& Weinberg, 2009), fiscal policies (Keeler \& Cretin, 1983), 
commitment (Duflo, Kremer \& Robinson, 2008; Sen, 1977, 2002b), health exercise (DellaVigna \& Malmendier, 2004, 2006), employment (DellaVigna \& Paserman, 2005), procrastination (Reuben, Sapienza \& Zingales, 2010), diet (Read \& van Leeuwen, 1998), subscription discipline (Oster \& Scott-Morton, 2005), animal care (Green \& Myerson, 1994; Mazur, 1987), and consumption (Milkman, Rogers \& Bazerman, 2008; Read et al., 1999; Wertenbroch, 1998). Failures to disciplinedly stick to plans for giving in to immediate desires (Ainslie \& Haslam, 1992; Read, Frederick \& Airoldi, 2012; Strotz, 1956) are explained by people caring less about future outcomes in the eye of future uncertainty (Luce \& Raiffa, 1957; Shackle, 1955), perceived risk (Mas-Colell, Whinston \& Green, 1995), and transaction costs (Chung \& Herrnstein, 1967; Epper, Fehr-Duda \& Bruhin, 2011; Frederick et al., 2002; Kirby \& Herrnstein, 1995; Mazur, 1987; Read, 2001). Presenting temporal snapshots for now and later concurrently helps overcome myopia (Puaschunder \& Schwarz, 2012). The wealth of behavioral economics theories on utility maximization deviations is - to this day - silent about decision making conflicts between preferences and values in the domains of information sharing and privacy.

\section{Information sharing and privacy}

The preference for communication is inherent in human beings as a distinct feature of humanity. Leaving a written legacy that can inform many generations to come is a humane-unique advancement of society. At the same time, however, privacy is a core human value. People choose what information to share with whom and like to protect some parts of their selves in secrecy. Protecting people's privacy is a codified virtue around the world to uphold the individual's dignity. Yet to this day, no utility theory exists to describe the conflict arising from the individual preference to communicate and the value of privacy.

\subsection{The humane-need for communication}

The act of conveying intended meanings from one entity or group to another through the use of mutually understood signs and semiotic rules is the act of communication. Communication is a key feature of humans, animals and even plants (Witzany, 2012). Steps inherent to all human communication are the formation of communicative motivation and reason, message composition as further internal or technical elaboration on what exactly to express, message encoding, transmission of the encoded message as a sequence of signals using a specific channel or medium, noise sources influencing the quality of signals propagating from the sender to one or more receivers, reception of signals and reassembling of the encoded message from a sequence of received signals, decoding of the reassembled encoded message and interpretation or sense making of the presumed original message (Shannon, 1948). Information sharing implying giving up privacy is at the core of communication. Communication can be verbal and nonverbal. Comprising very many different domains ranging from business, politics, interpersonal, social to mass media; communication is a humane-imbued wish and center core of every functioning society. In society, language is used to exchange ideas 
and embody theories of reality. Language is the driver of social progress (Orwell, 1949). Linguists find discourse and information sharing inseparable from socioeconomic societal advancement (Fowler, Hodge, Kress \& Trew, 1979).

Language and communication modes are implicit determinations of social strata (Orwell, 1949). Different institutions and media sources have different varieties of language and information sharing styles. Access to information is related to social status and market power. Information receipt is an implicit determinant to classify and rank people to assert institutional or personal status in society (Fowler et al., 1979). Mass communication echoes in economic cycles in the creation of booms and busts (Puaschunder, work in progress). Media is also a hallmark of propaganda and political control (Besley \& Prat, 2006). At the same time, privacy is a human virtue around the world.

\subsection{Privacy as a human virtue}

Privacy is the ability of an individual or group to seclude themselves, or information about themselves, and thereby share information about themselves selectively. The right to privacy grants the ability to choose which information about parts of the self can be accessed by others and to control the extent, manner and timing of the use of those parts we choose to disclose. Privacy comprises of the right to be let alone, the option to limit the access others have to one's personal information and secrecy as the option to conceal any information about oneself (Solove, 2008).

The degree of privacy varies in autonomy levels throughout individualistic and collectivism cultures. While the boundaries and contents protected and what is considered as private differ widely among cultures and individuals, the common sense in the world is that some parts of the self should be protected as private.

Privacy has a valued feature of being something inherently special or sensitive to a person, which can create value and specialty if shared with only a selected person or group. The domain of privacy partially overlaps with security, confidentiality and secrecy, which are codified and legally protected throughout the world, mainly in privacy laws but also in natural laws of virtues of integrity and dignity. Privacy is seen as a collective core human value and fundamental human right, which is upheld in constitutions around the world ${ }^{5}$ (Johnson, 2009).

In personal relations, privacy can be voluntarily sacrificed, normally in exchange for reciprocity and perceived benefits. Sharing private information can breed trust and bestow meaningfulness to social relations. Giving up privacy holds risks of uncertainty and losses, which are undescribed in economics and in particular the behavioral economics literature on intertemporal decision making (Gaudeul \& Giannetti, 2017). People tend to be more willing to voluntarily sacrifice privacy if the data gatherer is seen to be transparent as to what information is gathered and how the

\footnotetext{
5 E.g., Asian-Pacific Economic Cooperation, Australia, Brazil, Canada, China, European Union, Italy, Japan, Korea, Organisation for Economic Co-operation and Development, South Africa, United Kingdom, United Nations, United States, Universal Declaration of Human Rights - to name a few.
} 
information will be used (Oulasvirta, Suomalainen, Hamari, Lampinen \& Karvonen, 2014). Privacy as a prerequisite for the development of a sense of self-identity is a core of humanness (Altman, 1975). Privacy is often protected to avoid discrimination, manipulation, exploitation, embarrassment and risks of reputational losses, for instance, in the domains of body parts, home and property, general information of private financial situations, medical records, political affiliation, religious denomination, thoughts, feelings and identity. Technological shocks have a history of challenging privacy standards (Warren \& Brandeis, 1890). The age of instant messaging and big data, however, has leveraged the idea of privacy to another dimension. The concept of information privacy has become more significant as more systems controlling big data appear in the digital age.

\subsection{Privacy in the digital big data era}

The amount of big data stored each second has reached an all time high in the digital era. Internet privacy is the ability to determine what information one reveals or withholds about oneself over the internet, who has access to personal information and for what purpose one's information may be used. Privacy laws in many countries have started to adapt to changes in technology in order to cope with unprecedented constant information surveillance possibilities, big data storage opportunities and computational power peaks. For instance, Microsoft reports that 75 percent of U.S. recruiters and human-resource professionals use online data about candidates, often using information provided by search engines, social-network sites, photo and video sharing tools, personal web appearances like websites and blogs, as well as Twitter. Social media tools have become large-scale factories with unpaid labor. For instance, Facebook accounts for the largest social-network site with nearly 1,490 million members, who upload over 4.75 billion pieces of content about their lives and that of others daily. The accuracy of this information also appears questionable, with about 83.09 million accounts assumed to be fake. Aside from directly observable information, social media sites can also easily track browing logs and patterns, search queries or secondary information giving inferences about sexual orientation, political and religious views, race, substance use, intelligence and overall personality, mental status, individual views and preferences (Kosinski, Stillwell \& Graepel, 2013; Kosinski, Bachrach, Stillwell, Kohli \& Graepel, in press). As for the unprecedented possibilities to collect data, store big data and aggregate information that can be compared to big data Gestalt over time and society, privacy has leveraged into one of the most fragile areas in the electronic age, demanding for legal protection, regulatory control and e-ethics (Flaherty, 1989). Today, the existing global privacy rights framework in the digital age has been criticized to be incoherent, inefficient and in need for revision. Global privacy frameworks are demanded to be established. To this day there is no economic framework on information sharing and privacy control. While - for instance - Posner (1981) criticizes privacy for concealing information, which reduces market efficiency; Lessig (2006) advocates for regulated

online privacy. Yet to this day, there is no behavioral decision making frame to explain the privacy paradox of the individual predicament between the humane-imbued 
preference to communicate and share information versus the value of privacy. We have no behavioral economics description of the privacy paradox of inconsistency between privacy concerns and online information sharing behavior.

\section{A utility theory of information sharing and privacy}

Building on classical utility theory, individuals are constantly evaluating competing choice options. Individuals weight alternative options based on their expected utility derived. Indifference curves would then connect points on a graph representing different quantities of two goods, between which an individual is indifferent. In the case of the privacy paradox of information sharing preferences and privacy values, a person would weights whether or not to share information $s$ or choose the information to remain private $p$. The respective indifference curves would outline how much of information sharing $s$ and privacy $p$ can be enabled to end with the same utility given the budget of overall information held by the decision maker.

Graph 3 represents the respective indifference curves for information sharing $s$ and privacy $p$. That is, the individual has no preference for one combination or bundle of information sharing or privacy over a different combination of the same curve. All points on the curve hold the same utility for the individual. The indifference curve is therefore the locus of various points of different combinations of privacy and information sharing providing equal utility to her or him. Indifference curves are thereby seen to represent potentially observable behavioral patterns for individuals over information bundles. The indifference curve for information sharing $s$ and privacy $p$ is subject to communication and information constraints, hence all information budgets and communication opportunities. There is only a finite amount of information and there may be environmental conditions determining if people can exchange and share information. As exhibited in graph 3, the indifference curve for information sharing $s$ and privacy $p$ is a straight line given the assumption that information sharing or privacy are substitutes.

Graph 3: Indifference curve (blue line) for information sharing $s$ and privacy $p$ given the total information and communication constraint

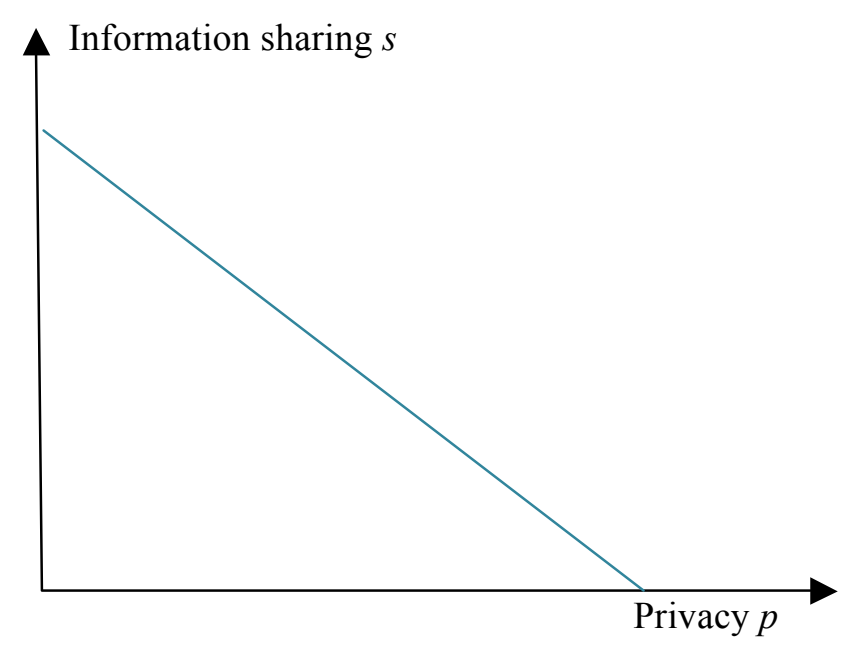


While in classical economics, an individual was believed to always being able to rank any consumption bundles by order of preference (Jevons, 1871); ${ }^{6}$ the indifference curve for information sharing $s$ and privacy $p$ subject to communication and information constraints may feature a hyper-hyperbolic element or temporal dimension. The information share moment may thereby be a reference point. At the moment of the information sharing decision, it may not be foreseeable what the future implication of the information sharing is. In addition, in the digital big data era, information share online may hold unforeseen risks of privacy merchants or social media capitalists that commercialize information reaping hidden benefits from the information provided (Etzioni, 2012; Puaschunder, 2017; The Economist, November $4,2017){ }^{7}$ The subjective additive utility of information shared tranche by tranche may underestimate the big data holder's advantage to reap benefits from information shared given unprecedented data storage and big data computation power advantages of the big data era. The big data information holder may therefore benefit from the history of information and the relation of the individual's information in comparison to the general population to an unknown degree given missing e-literacy and transparency. Comparison to the general public may lead to an implicit underrepresentation and hence discrimination of vulnerable groups. For instance, certain groups that may not be represented online will therefore likely face an underadvocacy of their rights and needs. Unprecedented computational power and storage opportunities have created the possibility to hoard information over time and put it in context with the rest of the population in order to draw inferences about the information sharer (The New York Times, November 14, 2017). ${ }^{8}$ The digital age and era of instant information sharing have therefore heralded problems of individuals who give in their basic humane need for information communication to become vulnerable over time.

While regular hyperbolic discounting captures a game theoretical predicament of the self now versus the self later, the information offering more of a Gestalt in the eyes of the big data holder, leverages hyperbolic discounting to a game theory against uncertainty on the end of the big data holder. The hyper-hyperbolic discounting fallibility therefore may describe that at the moment of information sharing, the individual has hardly any grasp what is implied in the giving up of privacy. The individual only focuses on the current moment trade-off between information sharing and privacy upholding, but hardly has any insights what the compiled information over time holds for big data moguls. As for holding computational and storage advantages, the social media big data moguls can form a Gestalt which is more than the sheer sum of the individual information shared, also in comparison to the general

\footnotetext{
6 http://www.econlib.org/library/YPDBooks/Jevons/jvnPE.html

7 https:/www.economist.com/news/leaders/21730871-facebook-google-and-twitter-were-supposed-savepolitics-good-information-drove-out

8 https://www.nytimes.com/2017/11/14/business/dealbook/taxing-companies-for-using-our-personaldata.html?rref=collection $\% 2$ Fsectioncollection $\% 2$ Fbusiness\&action=click\&contentCollection=busine ss\&region=stream\&module $=$ stream_unit\&version=latest\&contentPlacement $=8 \&$ pgtype $=$ sectionfront
} 
populace's data. The shared information can also be resold to companies (Etzioni, 2012; The New York Times, November 14, 2017). ${ }^{9}$ In relation to other people's information, the big data moguls can make predictions about their choices and behaviors. ${ }^{10}$ Information can also be used for governance purposes, for instance tax compliance and border control mechanisms (Puaschunder, 2017). Some governments have recently used big data to check the accuracy of tax reports but also to detect people's political views when crossing borders (Puaschunder, 2017). Lastly, the use of big data inferences also implies hidden persuasion means - nudging can be turned against innocent information sharers who have no long-term and computational advantage to foresee the impact of the information share (The Economist, November 4, 2017; Puaschunder, 2017). ${ }^{11}$

While behavioral economics hyperbolic discounting theory introduces the idea of time-inconsistency of preferences between an individual now and the same individual in the future; hyper-hyperbolic discounting underlines that in the case of information sharing preferences this fallibility is exacerbated since individuals lose control over their data and big data moguls can reap surplus value from the social media consumerworkers' information sharing and derive information complied over time and in relation to the general norm to draw inferences about the innocent information sharer. With the modern digital era, all these features open an information sharer versus information reaper divide in the big data age (Puaschunder, 2017).

\subsection{Expected utility and subjective probability in the digital big data era}

In accordance with neo-classical utility theory, alternatives are supposed to be weighted based on the resulting consequences dependent on uncertain aspects of the environment. But in the digital big data era, individuals simply lack an oversight of the consequences of information sharing. Assumptions on preferences of information sharing are skewed leading to an underestimation of the consequences of amalgamated information and private information evaluated in relation to other's data. Assignment of utilities to the consequences are underinflated. The utility of information sharing is thus the underweighted sum of the utilities of the consequences.

\subsection{Time preferences}

Following the standard neo-classical nomenclature of time preferences among the population, an information sharing preference over time is introduced. Multi-period decision making addresses that for each time period, another set of preferences for the

9 https://www.nytimes.com/2017/11/14/business/dealbook/taxing-companies-for-using-our-personaldata.html?rref=collection $\% 2$ Fsectioncollection $\% 2$ Fbusiness\&action=click\&contentCollection=busine

10 ss\&region $=$ stream \& module $=$ stream_unit\&version $=$ latest $\&$ contentPlacement $=8 \&$ pgtype $=$ sectionfront

10 https://www.nytimes.com/2017/11/14/business/dealbook/taxing-companies-for-using-our-personaldata.html?rref=collection $\% 2$ Fsectioncollection $\% 2$ Fbusiness\&action=click\&contentCollection=busine ss\&region $=$ stream\&module $=$ stream_unit\&version $=$ latest\&contentPlacement $=8 \&$ pgtype $=$ sectionfront

11 https://www.economist.com/news/leaders/21730871-facebook-google-and-twitter-were-supposedsave-politics-good-information-drove-out 
same options can be expected. The populace may therefore be theoretically categorizes into

(1) Extreme impatience: extreme information sharing as the individual values immediate pleasure of information sharing, information is shared without hesitation, impression management may play a role in this.

(2) Impatience: discounting the future impact of information, uninformed information sharing nature. This is the case if an individual shares information although having a hunch that this information sharing may create problems in the future, called the privacy paradox.

(3) Eventual impatience: discounting the future impact of information at some point in the future leads to controlled information sharing, very likely choosing what categories to expose to public.

(4) Time perspective: related to hyper-hyperbolic discounting awareness, individuals may control information sharing, for instance, these individuals may participate in social media only to reap information from others but not contribute additional information beyond what is required. This type has a controlled privacy and is engaged in social media solely to reap benefits of other's information from social media networks.

(5) No time preference: at the present time the individual neither discounts nor overcounts the future with respect to the present, which may be true for individuals who do not at all participate in social media communication and are blasé about information sharing and gaining information on social media,

(6) Persistence: consistent preference structure regarding information sharing may result in informed information sharing with no regrets, and

(7) Variety: consistently varying preference structure regarding information sharing, likely dependent on the content of information shared, may result in information sharing with regrets afterwards. These individuals have no stringent position towards information sharing or privacy preference, likely have categories for what to share and what not. This type varies in information preferences over time and by subject category.

This nomenclature addresses the problem of capturing valid preference structures over time that allow stringent predictions of choice behavior and strategies for future planning (Fishburn, 1968). The nomenclature also highlights that the selection of information sharing or privacy has an impact on our later choices. Addressing this predicament, Klein and Meckling (1958) suggest the best strategy given future uncertainties is to concentrate attention on immediate decisions that lead toward the main objective while preserving a reasonable degree of freedom in future choices. While Strotz (1957) considers the maximization of utility in an additive, discounted form over a continuous-time future and powerful research on hyperbolic discounting has unraveled pre-commitment and consistent planning as means to curb harmful decision making fallibility. Yet the age of social media generated big data may impose novel hyperbolic discounting fallibility onto the information-sharing 
individual (Behears, Choi, Laibson, Madrian \& Sakong, 2011; Chabris, Laibson \& Schuldt, 2008; Koopmans, 1964).

\subsection{Expected utility and subjective probability}

In accordance with neo-classical utility theory, alternatives are weighted based on the resulting consequences dependent on uncertain aspects of the environment. Assumptions on preferences between such alternatives lead to an assignment of utilities to the consequences and to the alternatives plus an assignment of subjective probabilities to the possible states of the environment. The utility of an alternative can therefore be written as a weighted sum of the utilities of the consequences. The weight for any alternative-consequence pair is the subjective probability associated with the states of the environment that yield the given consequence when the given alternative is used (Fishburn, 1968).

Regarding expected utility, the overall expected utility equation for information sharing and privacy reads

$u=\Sigma w \times u_{s}+w+u_{x}$,

(Equation 4.1)

whereby $w$ stands for weight, $u_{s}$ is the utility of information sharing and $u_{v}$ the utility of privacy.

The weighted expected utility equation reads

$u(P)=P\left(x^{1}\right) u_{s}\left(x^{1}\right)+P\left(x^{2}\right) u_{\mathcal{F}}\left(x^{2}\right)+\cdots+P\left(x^{1 n}\right) u\left(x^{m}\right)$

(Equation 4.2)

whereby $P\left(x^{1}\right) u_{s}\left(x^{1}\right)$ is the probability of information sharing utility and $P\left(x^{2}\right) u_{x}\left(x^{2}\right)$ the probability of privacy.

In the digital age, the utility of privacy is expected to have a marginal exponential value given the exponential rise of utility for the big data holder to reap benefits from data. The more data is held, the more complex relations can be unraveled by the big data holder. Information can be put into context of time and population correlates.

\section{Discussion}

In the age of instant communication and social media big data; the need for understanding people's trade off between communication and privacy has leveraged to unprecedented momentum. For one, enormous data storage capacities and computational power in the e-big data era have created unforeseen opportunities for big data hoarding corporations to reap hidden benefits from individual's information sharing.

In the $21^{\text {st }}$ century, the turnover of information and the aggregation of social informational capital has revolutionized the world. In the wake of the emergence of 
new social media communication and interaction methods, a facilitation of the extraction of surplus value in shared information has begun. Computational procedures for data collection, storage and access in the large-scale data processing have been refined for real-time and historical data analysis, spatial and temporal results as well as forecasting and now-casting throughout recent decades. All these advancements have offered a multitude of in-depth information on human biases and imperfections as well as social representations and collective economic trends (Minsky, 1977; Moscovici, 1988; Wagner \& Hayes, 2005; Wagner, Lorenzi-Cioldi, Mankova \& Rose, 1999; Puaschunder, 2015).

The digital age has brought about unprecedented opportunities to amalgamate big data information that can directly be used to derive inferences about people's preferences in order to nudge and wink them in the nudgitalist's favor. In today's nudgital society, information has become a source of competitive advantage. Technological advancement and the social media revolution have increased the production of surplus value through access to combined information. Human decisions to voluntarily share information with others in the search for the humane pleasure derived from communication is objectified in human economic relations. Unprecedented data storage possibilities and computational power in the digital age, have leveraged information sharing and personal data into an exclusive asset that divides society in those who have behavioral insights derived from a large amount of data (the nudgers) and those whose will is manipulated (the nudged).

The implicit institutional configuration of a hidden hierarchy of the nudgital society is structured as follows: Different actors engage in concerted action in the social media marketplace. The nudgital-brokers are owners and buyers of social media space, which becomes the implicit means of the production. In the age of instant global information transfer, the so-called social media industrialist-capitalist provides the social media platform, on which the social media consumer-workers get to share information about their life and express their opinion online for free. In their zest for a creation of a digital identity on social media platforms, a 'commodification of the self' occurs. Social media consumer-producer-worker are sharing information and expressing themselves, which contributes to the creation of social media experience (Puaschunder, 2017).

The hidden power in the nudgitalist society is distributed unevenly, whereby the social media consumer-workers are slaves, who receive no wages in return for their labor, falling for their own human nature to express themselves and communicate with one-another. Social media consumer-workers also engage in social media expression as for their social status striving in the social media platforms, where they can promote themselves. By posing to others in search for social status enhancement and likes, they engage in voluntary obedience to the social media capitalistindustrialist who sells their labor power product of aggregated information to either capitalists or technocrats. The social media consumer-worker's use value is inherent in their intrinsic motivation to satisfy a human need or want to communicate and gain 
respect from their community. The use value of the commodity is a social use value, which has a generally accepted use-value derived from others' attention and respect in the wake of information sharing in society. The social media provider gives the use value an outlet or frame, which allows the social media consumer-worker to express information, compare oneself to others and gain information about the social relation to others. The consumer-laborer thereby becomes the producer of information, releasing it to the wider audience and the social media industrialist. This use value only becomes a reality by the use or consumption of the social media and constitute the substance of consumption. The tool becomes an encyclopedic knowledge and joy source derived from the commodity.

But the use of social media is not an end in itself but a means for gathering more information that can then be amalgamated by the social media capitalistindustrialist, who harvests its use value to aid nudgers (Marx, 1867/1995). It is a social form of wealth, in form of social status and access to knowledge about others that the use value materializes on the side of the industrialist in the exchange value. For the social media industrialist, who is engaged in economic and governmental relations, the exchange value of the information provided by his or her social media consumer-laborers is the information released and consumption patterns studied. In exchange this allows to derive knowledge about purchasing and consumption patterns of the populace and therefore creates opportunities to better nudge consumers and control the populace. With the amalgamated information the social media industrialist-capitalist can gain information about common trends that can aid governmental officials and technocrats in ensuring security and governance purposes. Further, the social media platform can be used for marketing and governmental information disclaimers.

Exchange value is a social process of self-interested economic actors taking advantage of information sharing based on utility derived from consuming the social media. The social media industrialist-capitalist can negotiate a price based on the access to the social media consumer-worker's attention and sell promotion space to marketers. The exchange value of the commodity of information share also derives from the subjective perception of the value of amalgamated data. Exchanged information can be amalgamated by the social media industrialist-capitalist and traded to other market actors. Exchange value is derived from integrating everything the worker is and does, so both in his creative potential and how he or she relates to others. Exchange value also stems from the exchange of the commodity of amalgamated information that enables an elite to nudge the general populace. The amalgam of information as a premium signals the average opinion and how the majority reacts to changing environments, which allows inferences about current trends and predictions how to react to market changes.

Underlying motives may be the humane desire for prestige and distinction on both sides - the industrialist-capitalist's and the consumer-worker's. From the industrialist-capitalist's perspective, monetary motives may play a role in the 
materialization of information; on the consumer-worker's side it is the prestige gained from likes, hence respect for an online identity created. The benefits of the superior class are the power to nudge, grounded on the people's striving for prestige and image boosts. Impression management and emotions may play a vital role in seducing people to share information about themselves and derive pleasure for sharing (Evans \& Krueger, 2009; Horberg, Oveis \& Keltner, 2011; Lerner, Small \& Loewenstein, 2004). Social norms and herding behavior may be additional information sharing drivers (Paluck, 2009). The realization of prestige stems from creating a favorable image of oneself online, which signs up the workers in a psychological quasi-contract to provide more and more information online and in a self-expanding value. Prestige is also gained in the materialization of information as asset by the capitalist-industrialist, who reaps the surplus value of the commodification of the self of the consumer-worker (Marx, 1867/1995). The social media capitalist-industrialist therefore increases their capital based on the social media consumer-worker's innocent private information share. The social media capitalist-industrialist also accumulated nudgital, the power to nudge.

This information sharing opens a gate for the social media provider to reap surplus value from the information gathered on social platforms and to nudge the social media consumer-producers or resell their amalgamated information to nudgers. Crucial to the idea of exploitation is the wealth or power of information in the digital age. Surplus of information can be used to nudge in markets and by the force of governments. To acknowledge social media consumers as producers lead to the conclusion of them being underpaid workers in a direct wage labor exploitation. Surplus gravitates towards the social media owning class. Information becomes a commodity and commodification a social product by the nature of communication. Commodification of information occurs through the trade of information about the consumer-worker and by gaining access to nudge consumer-workers on social platforms. The transformation of a labor-product into a commodity occurs if information is used for marketing or governance purposes to nudge people. In the contemporary big data society, the nudged social media user therefore end up in a situation where they are unwaged laborers, providing the content of entertainment within social media, whereas the social media industrialist-capitalist, who only offers the information brokerage platform, reaps benefits from the amalgamated information shared. Not just labor power but the whole person becomes the exchange value, so one could even define the consumer-worker as utility-slave.

The technological complexity of digital media indicates how interrelated social, use and exchange value creation are. All commodities are social products of labor, created and exchanged by a community, with each commodity producer contributing his or her time to the societal division of labor. Use value is derived by the consumerworker being socially related insofar as private consumption becomes collective. The use value thereby becomes the object of satisfaction of the human need for social care and want for social interaction. The use value becomes modified by the modern 
relations of production in the social media space as the consumer-worker intervenes to modify information. What the consumer-worker says on social media, for the sake of communication and expression but also in search for social feedback, is confined by the social media industrialist-capitalist, who transforms the use value into exchange value by materializing the voluntary information share by summing it up and presenting it to nudgers, who then derive from the information marketability and nudgitability of the consumer-workers. All information sharing has value, or labor value, the abstract labor time needed to produce it. The commodification of a good and service often involves a considerable practical accomplishment in trade. Exchange value manifests itself totally independent of use value. Exchange means the quantification of data, hence putting it into monetary units. In absolute terms, exchange value can be measured in the monetary prices social media industrialistcapitalists gain from selling advertisement space to nudging marketers but also to public and private actors who want to learn about consumer behavior in the digital market arena and influence consumers and the populace. The exchange value can also be quantified in the average consumption-labor hours of the consumers-workers. While in the practical sense, prices are usually referred to in labor hours, as units of account, there are hidden costs and risks that have to factored into the equation, such as, for instance, missing governmental oversight and taxing of exchange value.

Overall, there is a decisive social role difference between the new media capitalist-industrialist and the social media consumer-worker. The social media provider is an industrialist and social connection owner, who lends out a tool for people to connect and engage with. As the innovative entrepreneur who offers a new media tool, the industrialist also becomes the wholesale merchant in selling market space to advertisement and trading information of his customers or workers, who are actively and voluntarily engaging in media tools (Schumpeter, 1949). The social media consumers turn into workers, or even slaves if considering the missing direct monetary remuneration for their information share and since being engaged in the new media tool rather than selling their labor power for money in the market place holds opportunity costs of foregone labor. While selling their commodity labor power, the social media consumer-workers are also consumers of the new media tool laden information, which can be infiltrated with advertisement. The social media capitalist-industrialist not only reaps exchange value benefits through access to people's attention through selling advertisement space, but also grants means to nudge the consumers into purchasing acts or wink the populace for governance authorities (Marx, 1867/1995). The social media capitalist-industrialist thereby engages in conversion of surplus value through information sharing into profit as well as selling attention space access and private data of the consumer-workers.

When the new media consumer-workers' amalgam of provided information gets added up to big data sets, it can be used by capitalists and governance specialists. Over time the nudgital society emerges, as the nudging social media industrialistcapitalists form a Gestalt of several bits and pieces put together about the nudged 
social media consumer-producer-worker-slaves. Information gets systematically added up providing invaluable behavioral insights. Information in its raw form and in amalgamated consistency then gets channeled from the broad working body on social media into the hands of a restricted group or societal class. This circulation of information and the distribution into those who provide a medium of information exchange and those who exchange information that then forms a society in those who nudge and those who are nudged implying an inherent social class divide.

In the nature of exchange, nudgital becomes an abstract social power, a property claim to surplus value through information. Value can be expropriated through the exchange of information between the industrialist-capitalist and the nudgitalist. Exchange value has an inherent nature of implicit class division. Exchange value represents the nudgitalists' purchasing power expressed in his ability to gain labor time that is required for information sharing as a result of the labor done to produce it and the ability to engage in privacy infringements. The social media industrialist-capitalists implicitly commands labor to produce more of data through social nudging and tapping into humane needs to communicate and express themselves, whereby he or her use a reacting army of labor encouraging information share through social gratification in the form of likes and emoticons. The reacting army of labor is comprised of social media users, who degrade into hidden laborers that are not directly compensated for their information share and cheerleading others to do the same. The nudgital society's paradox is that information sharing in the social compound gets pitted against privacy protecting alienation.

The nudgitalist exploitation also holds when technocrats use heuristics and nudges to create selfish outcomes or undermine democracy. Ethical abysses of the nudgital society open when the social media is used for public opinion building and public discourse restructuring. Social media not only allows to estimate target audience's preferences and societal trends but also imposes direct and indirect influence onto society by shaping the public opinion with real and alternative facts. Government officials' gaining information about the populace that can be used to interfere in the democratic voting process, for instance in regards to curbing voting behavior or misinformation leading people astray from their own will and wishes. The social intertwining of the media platform and the democratic act of voting has been outlined in recent votes that were accused to have been compromised by availability heuristic biases and fake news. Data can also be turned against the social media consumer-worker by governance technocrats for the sake of security and protection purposes, for instance, social media information can be linked together tax verification purposes.

Governments have been transformed under the impact of the digital revolution. Instant information flow, computational power and visualization techniques, sophisticated computer technologies and unprecedented analytical tools allow policy makers to interact with citizens more efficiently and make well-informed decisions based on personal data. New media technologies equip individuals with constant 
information flows about informal networks and personal data. Novel outreach channels have created innovative ways to participate in public decision making processes with a partially unknown societal impact at a larger scale, scope and faster pace than ever before. Big data analytics and the internet of things automate many public outreach activities and services in the $21^{\text {st }}$ century. Not only do we benefit from the greatly increasing efficiency of information transfer, but there may also be potential costs and risks of ubiquitous surveillance and implicit persuasion means that may threaten democracy. The digital era governance and democracy features datadriven security in central and local governments through algorithmic surveillance. Open source data movements can become a governance regulation tool. In the sharing economy public opinion and participation in the democratic process has become dependent on data literacy. Research on the nudgital society holds key necessary information about capacity-building and knowledge sharing within government with respect for certain inalienable rights of privacy protection. The nudgital society's paradox that information sharing in the social compound gets pitted against privacy protecting alienation requires an ideological superstructure to sustain and tolerate hidden exploitation.

All these features are modern times phenomena as the technology and big data creating computational power is currently emerging. The transferability of the commodity of information itself, hence the big data amalgamation over time and space to store, package, preserve and transport information from one owner to another appears critical. The legal leeway to allow private information sharing implicitly leads to individuals losing their private ownership rights to the commodity of information upon release on social media and the right to trade information. The transferability of these private rights from one owner to another may infringe on privacy protection, human rights and humane dignity upholding mandates.

Not only pointing at the ethical downfalls of the nudgital society, also defining social media users as workers is of monumental significance to understand the construction of the nudgital society and bestow upon us social media consumerworkers labor rights. The technical relationship between the different economic actors are completely voluntary and based on trust (Puaschunder, 2016). The creation of use value is outsourced to the community (e.g., in likes) and the share of information about the workers from the social media capitalist to the market or nudgitalists remains without a clear work contract and without protection of a labor union. The worker-employer relationship needs to be protected and a minimum wage should settle for the market value of the worker producing during the working day. Wages would be needed to maintain their labor power of the workers minus the costs of the production. Unpaid laborers should not only be compensated for their opportunity costs of time but should enjoy the workers' privilege of right to privacy, prevention of misuse of the information they share and have the right to access to accurate information but also protection from nudging in the establishment of the right to voluntary fail. 
The nature of making profit from information in exchange value is questionable. Information exchange of the industrialist-capitalist is different than neoclassical goods and services trade insofar since for the capitalist-industrialist making money off privacy and the consumer-workers share of information without knowledge and/or control over the recipient of the amalgamated mass of privacy released. Workers are never indifferent to their use value and their inputs may also produce unfavorable outcomes for them. The exchange value will sell for an adequate profit and is legally permitted, yet it can destroy the reputation and standing as well as potentially the access of the individual to country entrance if considering the proposed social media information release mandate at border controls. Care must be taken for privacy infringement and the product of amalgamated big data and how useful it is for society.

By shedding light on these risks of the social media age and the implicit dynamism of capitalism forming around information, a social formation of social media workers' right can be heralded. Social media user-workers should be defined to hold inalienable rights to privacy and be forgotten (part 4.1), to be protected from data misuse of information they share (part 4.2), they should be granted the right to access of accurate information (part 4.3) and - in light of the nudgitalist audacity the right to fail (part 4.4).

\subsection{People's right to privacy and to be forgotten}

The transformation of a use value into a social use value and into a commodity has technical, social and political preconditions. Information gets traded and ownership of privacy transferred in information sharing. Upon sharing information on social media, the consumer-worker bestows the social media capitalist-industrialist with access to previously private information. The social media capitalists then transforms the information into use value by offering and selling the bundled information to nudgitalists, who then can draw inferences about certain consumer group's preferences and guide their choices.

Overall, the nudgital society leads to a dangerous infringement upon the independence of individuals in their freedom of choice and a social stratification into those who have access to the amalgamated information of social media consumerworkers. There is a trade-off between communication and privacy in an implicit contract of the use of personal data. Power is exercised through the accumulation of information, including the quality of insatiability of social media consumer-workers to constantly upload information and the social media capitalist-industrialist reaping profits from selling it.

Social media thereby reveals to hold a sticky memory that allows storage of information in the international arena eternally. Privacy and information share regulations depend on national governments. For instance, in the commodification of privacy, the EU is much more beneficial to consumers than that of the US. Data protection and commercial privacy are considered as fundamental human rights to be safeguarded in Europe. In contrast, the US approach towards commercial privacy 
focuses on only protection the economic interests of consumers. Current privacy regulations are considered as not sufficient in targeting actions that cause noneconomic and other kinds of harm to consumers.

Privacy and information sharing guidelines appear to be culturally-dependent phenomena. Information about privacy boundary conditions can be obtained from the transatlantic dialog between the US and Europe on privacy protection. While in Europe health care data is public, in Canada, there is a public interest to make the data more public. The EU's privacy approach is based on Article 7 and 8 of the Charter of the Fundamental Rights of the EU, which grants individuals rights to protection, access and request of data concerning him or herself. European privacy is oriented around consumer consent. The 2016 EU General Data Protection Regulation (GDPR) ruled the right to be forgotten under certain circumstances. Consumer consent and dealing with incomplete, outdated and irrelevant information is legally regulated. GDPR establishes regulatory fines for non-complying companies applicable to foreign companies whose data processing actions are related to 'good and services' that they provide to data subjects in the EU, so also including US companies operating in the virtual space accessible by European citizens. The EU privacy approach offers member states flexibility in data management for national security and other exceptional circumstances but also protects civilians from common potential circumstances for data abuse; while there are standardized data management policy procedures regardless of a companies' country-of-origin or operational locations. The EU's privacy approach has higher regulatory costs, is not specified by sectors and the right to be forgotten still needs enforcement validity.

The US approach to privacy is sector specific. Commercial privacy is pitted against economic interests and neither seen as civil liberty nor as constitutional right. US privacy is regulated by the Federal Communications Commission (FCC) and the Federal Trade Commission (FTC). Overall in the US, the general definitions of unfair and deceptive give the FTC a wider scope for monitoring and restricting corporate privacy infringements. The FTC has a wide variety of tools for data protection, yet the responsibility is split between the FTC and the FCC, which increases bureaucratic and regulatory costs and limits industry oversight.

So while the EU framework treats commercial privacy as a basic human right leading to a more extensive protection of individual's privacy including data collection, use and share, the EU framework is also non-sectoral and allows sovereign nation states to overrule common data management policies for the sake of national security and protection. The US framework lacks a centralized privacy regulation approach, yet is sector but split regarding oversight in the domains of the FCC and FTC.

\subsection{People's right to prevent misuse of information they share}

By US standards, social media is required by the FTC to ask users for permission if it wants to alter its privacy practices. Under Section 5 of the FTC Act that states that (1) unfair practices are causes or is likely to cause substantial injury to consumers or 
cannot reasonably be avoided by consumers; and (2) deceptive practices are practices that likely are misleading or actually misleading the consumer.

In August 2016 decision of WhatsApp to sharing more user data, especially user phone numbers - with Facebook in order to track customer-workers' use metrics and targeted user advertising. This decision faced a huge backlash in the EU, where data sharing was ordered to be halted and Germany deemed its practices as illegal. In the US the Federal Trade Commission (FTC) began reviewing joint complaints from consumer privacy groups. The recent WhatsApp data sharing is a possible violation of this requirement since it only allowed consumers to opt out of most of the data sharing while lacking clarity and specificity. WhatsApp's restrictive opt out option and incomplete data sharing restrictions were argued to be perceived as unfair and deceptive (Tse, in speech, March 25).

\subsection{People's right to access to accurate information}

In the nudgital society, profits appear in the circuit of information and take on different forms in the new media age. The possibility of trading information and reaping benefits from information sharing of others determines the unequal position of people in society. The possession of knowledge stems from the surplus derived from the activity of production, hence the information share of social media consumer-producers. This confrontation of labor and consumption is not apparent in the modern marketplace. The class division remains quite invisible in the implicit workings of the system.

The nudgitalist act becomes problematic when being coupled with infiltration with fake news and alternative facts that curb democratic acts, e.g. manipulating voting behavior. Ethical questions arise if it there is a transparency about the capitalist's share of information and a fair social value benefits distribution among the capitalist and the worker. In addition, under the cloak of security and protection, privacy infringements by sharing information with the nudgitalist is questionable. By outlining these market procedures, fairness in the distribution of gains should be accomplished and privacy infringing information sharing limited or at least guided by the legal oversight. Access to information about the storage, preservation, packaging and transportation of data is non-existent, demanding for more information about behind-the-scenes' social media conduct. Transforming private information from use value to exchange value is an undisclosed and therefore potentially problem-fraught process that holds implicit inequality within itself. From a societal standpoint, also the missing wealth production in the social media economy appears striking. Thereby the dangers of information release and transfer and the hidden exchange value accrued on the side of the media innovator is left unspoken. The importance of shedding light on such, though, is blatant as for stripping the populace from inalienable rights of privacy while reaping benefits at the expense of their susceptibility. Nudges in combination with misinformation and power abuse in the shadow of subliminal manipulation can strip the populace from democratic rights to choose and voluntary fail. 


\subsection{People's right to choose and fail}

In the personal information sharing age and nudgital society, attention must be given to privacy and human dignity. The nudgital society opens a gate to gain information about consumer choices and voting preferences. The uneven distribution of key information about people's choices opens a gate to tricking people into choices. The so-called nudging attempt though raises ethical questions about human dignity and the audacity of some to know better what is better for society as a whole. Because governance is a historical process, no one person can control or direct it, thereby creating a global complex of governance connections that precedes the individual administration. Structural contradictions describe the class struggle between the nudged in opposition to the nudgers in the nudgital society. Since societal actors who involuntarily are nudged are separated from an active reflection process when being nudged, the moral weight is placed on the nudger. Though democratically elected and put into charge, the nudgers checks-and-balances of power seem concentrated and under disguise through the middle man of social media capitalist-industrialists who collect information. Rather focusing on how to trick people into involuntary choices, the revelations should guide us to demand to educate people on a broad scale about their fallibility in choice behavior.

In a self-enlightened society, people have a right to voluntary fail. Nudging implies a loss of degrees of freedom and disrespect of human dignity, hence the nudgital society will lead to structural contradictions. Their rational thinking and voluntary engagement in governmentally-enforced action becomes divorced from rational reflection. No one entity should decide to control or direct other's choices, thereby creating a global complex of social connections among the governed for the sake of efficiency for the common good. The economic formation of human decision making in society should never precede the human voluntary decision.

There is an inherent inequality of social positions, manifested primarily in the respective capacities of reaping benefit from amalgamated information, which leads to a disparity of social position. The distribution of power leads to a natural order of human activity, in which the nudgers are in charge of nudging the populace. Moral value is separated from economic value and hence placing the fate of the populace into the arms of the behavioral economists raises problems of lack of oversight and concentration of objective economic value rule in the nudgital society.

Overall, with the communication on the nudgital society just having started, it remains on us to redesign the apparatus of production in ways that make impossible the infringement on private information through the natural tendency to share information, care about others and express oneself. Governance crises are rooted in the contradictory character of the value creation through big data. The formation of value is a complex determination and we still need more research to understand the deep structures of market behavior in the digital age. 


\section{Conclusion and future prospects}

The article presented a first theoretical introduction of a utility theory of information sharing and privacy. As a next research step, a stringent hypotheses testing of the presented problem is recommended. For instance, future research projects featuring a multi-methodological approach will help gain invaluable information about the actual performance and behavior regarding information sharing and privacy upholding. Interaction of individual on social media should be scrutinized in order to derive realworld relevant economic insights for legal and policy making purposes alongside advancing an upcoming scientific field. Following empirical investigations should employ a critical survey of the intersection of analytic and behavioral perspectives to decision making in information sharing. Literature discussion featuring a critical analysis how to improve e-literacy should be coupled with e-education and enhancement of e-ethicality. Research should be directed towards a critical analysis of the application of behavioral economics on hyper-hyperbolic discounting in the digital age. In the behavioral economics domain, both approaches, studying the negative implications of information sharing and decision making to uphold privacy but also finding ways how to train new media users wiser decisions should be explored. Interdisciplinary viewpoints and multi-method research approaches should be covered in the heterodox economics readings but also in a variety of independent individual research projects. Research support and guidance should be targeted at nurturing interdisciplinary research interests on privacy and information sharing in the fields of behavioral economics and public affairs.

More concretely, future studies should define the value that data has to individuals and data sovereignty in the international context. When people share information, they should be informed to consider what the benefit and value from sharing is for them and what the benefit for social media industrialists-capitalists is. The sovereignty of data and the human dignity of privacy should become debated as virtual virtue in the $21^{\text {st }}$ century. Individuals should be informed that sharing data is a personal security risk, if considered to be asked for social media information upon entry of a country.

Future studies should describe what companies and institutions constitute the complex system help establishing the nudgital society and the influence that social media has. Politicians may use various channels and instruments to manipulate the populace with targeted communication. The implicit underlying social structure of the nudgital society based on a complicated information gathering machinery should become subject to scrutiny and how, in particular, the nudgital class division is supported by a comprehensive social network data processing method. How social media advertising space can be used to specialize on targeted propaganda and misleading information to nudge the populace in an unfavorable way should be unraveled.

In the recent US election the profit and value of detailed market information has been found to have gained unprecedented impetus. Future research should also draw 
a line between the results of the 2016 US presidential election, and the study of heuristics to elucidate that heuristics played a key role in Trump's election as they made people less likely to vote logically. This would be key as it would help explain how people chose to vote, and why they do not always make the most logical choice when voting. This line of research could help to more accurately promote future elections' candidates, how to better predict election outcomes and how to improve democracy.

In addition, nudging through means of visual merchandising, marketing and advertising should be captured in order to uphold ethical standards in social media. Nudging's role in selling products, maximizing profits but also creating political trends should be uncovered. While there is knowledge on the visual merchandising in stores and window displays, little appears to be known how online appearances can nudge people into making certain choices. In particular, the familiarity heuristic, anchoring and the availability heuristic may play a role in implicitly guide people's choices and discreetly persuade consumers and the populace. Not to mention advancements of online shopping integrity and e-commerce ethics, the prospective insights gained will aid uphold moral standards in economic market places and hopefully improve democratic outcomes of voting choices.

Future research should also investigate how search engines can be manipulated to make favorable sources more relevant and how artificial intelligence and social networks can become dangerous data manipulation means. The role of data processing companies may be studied in relation to the idea of data monopoly advantages - hence situations in which data processing companies may utilize data flows for their own purposes to support sponsored causes or their own ideals. Due to the specific time period of the digital age not extrapolations to past time periods is possible but the results appear useful in determining future behaviors.

The current research in this area lacks empirical evidence, demanding for further investigations on how nudges can directly impact individual's choices and new media can become a governance manipulation tool. What social instruments are employed on social media and what prospects data processing has in the light of privacy infringement lawsuits should be uncovered. How social media is utilized to create more favorable social personas for political candidates should be explored. How internet online presences allow to gain as much attraction as possible for the presence of political candidates is another question of concern. All these endeavors will help outlining the existence of social media's influence in governance and data processing to aid political campaigning in order to derive inferences about democracy and political ethicality in the digital age. Another area of concern is how selective representations influence the voting population and what institutions and online providers are enabling repetitiveness and selectivity. How gathered individual information is used to parse data to manipulate social internet behavior and subsequent action is another topic to be investigated. Future research goals will include determining what this means for the future political landscape and how 
internet users should react to political appearances online. Consumer education should target at educating social media users about their rights and responsibilities on how to guard their own and other's privacy. E-ethicality trainings could target at strengthening the moral impetus of big data and artificial ethicality in the digital age. Moral trade-offs between privacy infringements and security should also become subject to scrutiny.

How social media tools nudge people to not give everything at once but put it together in a novel way that it creates surplus, should be analyzed. In small bits and pieces individuals give up their privacy tranche be tranche. Small amounts of time are spent time for time. People, especially young people, may have a miscalibration about the value of information released about them. Based on hyperbolic discounting myopia, they may underestimate the total future consequences of their share of privacy.

Future studies should also look into the relationship between individual's political ideologies and how they use and interact on social media, especially with a focus on the concept of fake news and alternative facts. Where do these trends come from and who is more susceptible to these negative impacts of the digital society? Has social media become a tool to further polarize political camps, is needed to be asked. In addition, innovative means should be found to restore trust in media information and overcome obstacles such as the availability heuristic leading to disproportionate competitive advantages of media controlling parties. Information should be gathered how we choose what media to watch and if political views play a role in media selection and retention. Does distrust in the media further political polarization and partisanship, needs to be clarified.

The preliminary results may be generalized for other user-generated web contents such as blogs, wikis, discussion forums, posts, chats, tweets, podcastings, pins, digital images, videos, audio files, advertisements but also search engine data gathered or electronic devices (e.g., wearable technologies, mobile devices, Internet of Things). Certain features of the nudgital society may also hold for tracking data, including GPS, geolocation data, traffic and other transport sensor data and CCTV images or even satellite and aerial imagery. All preliminary results should be taken into consideration for future studies in different countries to examine other cultural influences and their effects on social class and heuristics.

Promoting governance through algorism offers novel contributions to the broader data science and policy discussion (Roberts, 2010). Future studies should also be concerned with data governance and collection as well as data storage and curation in the access and distribution of online databases and data streams of instant communication. The human decision making and behavior of data sharing in regards to ownership should become subject to scrutiny in psychology. Ownership in the wake of voluntary personal information sharing and data provenance and expiration in the private and public sectors has to be legally justified (Donahue \& Zeckhauser, 2011). In the future, institutional forms and regulatory tools for data governance 
should be legally clarified. Open, commercial, personal and proprietary sources of information that gets amalgamated for administrative purposes should be studied and their role in shaping the democracy. In the future we also need a clearer understanding of the human interaction with data and their social networks and clustering for communication results. The guarantee of safety of the information and the guarantee of the replacement or service, should a social media fail its function to uphold privacy law as intended, is another area of blatant future research demand. Novel qualitative and quantitative mixed methods featuring secondary data analysis, web mining and predictive models should be tested for holding for the outlined features of the new economy alongside advancing randomized controlled trials, sentiment analysis and smart contract technologies. Ethical considerations of machine learning and biologically inspired models should be considered in theory and practice. Mobile applications of user communities should be scrutinized.

As for consumer-worker conditions, unionization of the social media workers could help uphold legal rights and ethical imperatives of privacy, security and personal data protection. Data and algorithms should be studied by legal experts on licensing and ownership in the use of personal and proprietary data. Transparency, accountability and participation in data processing should also become freed from social discrimination. Fairness-awareness programs in data mining and machine learning coupled with privacy-enhancing technologies should be introduced in security studies of the public sector. Public rights of free speech online in the dialogue based on trust should be emphasized in future educational programs. Policy implications of the presented ideas range from security to human rights and law to civic empowerment. Citizen empowerment should feature community efforts to protect data and information sharing to be free of ethical downfalls. Social media use education should be ingrained in standard curricula and children should be raised with an honest awareness of their act of engagement on social media in the nudgital society of the digital century.

Future research may also delve into moderator variables of the utility derived from information sharing and privacy. For instance, extraversion and introversion could be moderating the overall pleasure derived from communication or silence. Future research may also address prescriptive recommendations how to educate individuals about the risks and dangers of information sharing in the digital age. Attention must also be paid to how to uphold accuracy in times of fake news and selfcreated social information. Certain societal segments that are not represented strongly online should somehow be integrated into big data in order to democratize the information, which is considered as big data 'norm,' or standard by which the social media user is measured on. At the same time, psychologically guide studies could unravel a predictive approach and validate the outlined ideas' validity by testing the proposed theoretical assumptions in laboratory and field study settings. In particular, the proposed nomenclature's validity could be studied and the percentage of information sharing types captured in the population. The moderator variable age 
could be phased in as it appears to be conundrum why younger people, who have more to lose given a longer time ahead to live are in particular prone to use new social media and lavishly share their lives in e-blasts to public. Regarding direct implications, a tax may be used to offset problems of the costs and risks of social media privacy infringements in the big data era. ${ }^{12}$ Drawing from utility usually measured by the willingness to pay different amounts of money for different options, laboratory experiments may operationalize the value of privacy by measuring how much money people would be willing to pay for repurchasing their data or having a social media account that can only be viewed but no personal data can be resold or put in context to others. These attempts could also serve as a guideline for policy regulations and free market solutions. Social media could offer services of having accounts that are private in that sense that no surplus value can be reaped by reselling information or big data storage and computation can occur. This may serve as an indicator of revealed preferences of social media privacy. The privacy paradox may be scrutinized in behavioral economics laboratory and field experiments. Potential individual influencing factors such as gender, age, trust and personality differences may be tested for in order to retrieve information on how to educate the social media user and regulate the social media provider. Regarding regulation, splitting social media power cartels may be one solution to decrease the big data social media user disadvantage. Taxation for information sharing may create another incentive to slow down unreflected information share. The tax revenues could be used to offset some of the societal costs of privacy infringement. In addition, fines for privacy infringement could help to uphold e-ethics in the digital age.

Overall, the presented piece can also serve as a first step towards advocating for education about information sharing in order to curb harmful information sharing discounting fallibility. From legal and governance perspectives, the outlined ideas may stimulate the e-privacy infringement regulations discourse in the pursuit of the greater goals of democratization of information, equality of communication surplus and upheld humane dignity and e-ethics in the big data era.

\section{Acknowledgment}

Financial support of the Eugene Lang College of The New School, Fritz Thyssen Foundation, the Janeway Center Fellowship, New School for Social Research, Prize Fellowship, the Science and Technology Global Consortium, the University of Vienna, and Vernon Arts and Sciences is gratefully acknowledged. The author thanks Professor Andrea Prat for a most interesting lecture on 'Industrial Organization' at Columbia University during Fall 2017. All omissions, errors and misunderstandings in this piece are solely the author's.

\footnotetext{
$12 \mathrm{https}: / /$ www.nytimes.com/2017/11/14/business/dealbook/taxing-companies-for-using-our-personaldata.html?rref=collection\%2Fsectioncollection\%2Fbusiness\&action=click\&contentCollection=business \&region=stream\&module=stream_unit\&version=latest\&contentPlacement=8\&pgtype=sectionfront
} 


\section{RAIS COLLECTIVE VOLUME - ECONOMIC SCIENCE}

\section{References}

Alchian, A.A. (1953). The meaning of utility measurement. American Economic Review, 32, 26-50.

Ainslie, G. (1992). Picoeconomics: The interaction of successive motivational states within the person. Cambridge: Cambridge University Press.

Ainslie, G. \& Haslam, N. (1992). Hyperbolic discounting. In G. Loewenstein \& I. Elster (Eds.), Choice Over Time. New York: Russel Sage.

Alberini, A. \& Chiabai, A. (2007). Discount rates in risk versus money and money versus money tradeoffs. Risk Analysis, 27, 2, 483-498.

Allport, G.W (1979). The nature of prejudice. Reading: Addison-Wesley.

Altman, I. (1975). The environment and social behavior: Privacy, personal space, territory, and crowding. Monterey: Brooks.

Arrow, K.J. (1951). Alternative approaches to the theory of choice in risk-taking situations. Econometrica, 19, 404-437.

Arrow, K.J. (1958). Utilities, attitudes, and choices: A review note. Econometrica, 26, 1-23.

Arrow, K.J. (1978). Extended sympathy and the possibility of social choice. Philosophia, 7, 2, 223237.

Aumann, R.J. \& Kruskal, J.B. (1958). The coefficients in an allocation problem. Naval Research Logistics Quarterly, 5, 111-123.

Aumann, R.J. \& Kruskal, J.B. (1959). Assigning quantitative values to qualitative factors in the naval electronics problem. Naval Research Logistics Quarterly, 6, 1-16.

Badger, G.J., Bickel, W.K., Giordano, L.A., Jacobs, E.A., Loewenstein, G. \& Marsch, L. (2007). Altered states: The impact of immediate craving on the valuation of current and future opioids. Journal of Health Economics, 26, 5, 865-876.

Bazerman, M. H. \& Tenbrunsel, A. E. (2011). Blind spots: Why we fail to do what's right and what to do about it. Princeton: Princeton University Press.

Becker, G.M. \& McClintock, C.G. (1967). Values: Behavioral decision theory. Annual Review of Psychology, 18, 239-286.

Becker, G.S. \& Murphy, K.M. (1988). A theory of rational addiction. The Journal of Political Economy, 96, 675-700.

Beshears, J.L., Choi, J.J., Laibson, D.I., Madrian, B.C. \& Sakong, J. (2011). Self-control and liquidity: How to design a commitment contract. RAND Working Paper Series, WR- 895-SSA.

Besley, T. \& Prat, A. (2006). Handcuffs for the grabbing hand? Media capture and government accountability. American Economic Review, 96, 3, 720-736.

Bernoulli, D. (1954). Specimen theories novae de mensura sortis. Commentarii Academiae Scientiarum Imperialis Petropolitanae, 5, 175-192.

Bosworth, R., Cameron, T.A. \& DeShazo, J.R. (2006). Preferences for preventative public health policies with jointly estimated rates of time preference. School of Public Health and International Affairs: North Carolina State University.

Bowles, S. (2004). Microeconomics: Behavior, Institutions \& Evolution. Princeton: Princeton University Press.

Chabris, Ch., Laibson, D. \& Schuldt, J. (2008). Intertemporal choice. New York: Palgrave Dictionary of Economics. 
Camerer, C.F., Loewenstein, G. \& Rabin, M. (2004). Advances in behavioral economics. Princeton: Princeton University Press.

Cartwright, E. (2011). Behavioral economics. London, UK: Routledge.

Cairns, J. \& van der Pol, M. (2008). Valuing future private and social benefits: The disountined utility model versus hyperbolic discounting models. Journal of Economic Psychology, 21, 2, 191-205.

Cameron, T.A. \& Gerdes, G.R. (2003). Eliciting individual-specific discount rates. Department of Economics: University of Oregon.

Chabris, Ch., Laibson, D. \& Schuldt, J. (2008). Intertemporal choice. New York: Palgrave Dictionary of Economics.

Chapman, G.B. (1996a). Expectations and preferences for sequences of health and money. Organizational Behavior and Human Decision Processes, 67, 59-75.

Chung, S.H. \& Herrnstein, R.J. (1967). Choice and delay of reinforcement. Journal of Experimental Analysis of Behavior, 10, 1, 67-74.

Colinsky, J. (1996). Why bounded rationality? Journal of Economic Literature, 34, 669-700.

Coller, M. \& Williams, M.B. (1999). Eliciting individual discount rates. Experimental Economics, 2, 2 , 107-127.

Debreu, G. (1958). Stochastic choice and cardinal utility. Econometrica, 26, 440-444.

Debreu, G. (1960). Topological methods in cardinal utility theory. In K.J. Arrow, S. Karlin and S. Suppes (Eds.), Mathematical models in the social sciences, pp. 16-26. Stanford, CA: Stanford University press.

Debreu, G. (1964). Continuity properties of Paretian utility. International Economic Review, 5, 285 293.

DellaVigna, St. \& Malmendier, U. (2004). Contract design and self-control: Theory and evidence. Quarterly Journal of Economics, 119, 2, 353-402.

DellaVigna, St. \& Malmendier, U. (2006). Paying not to go to the gym. American Economic Review, 96, 3, 694-719.

DellaVigna, St. \& Paserman, M.D. (2005). Job search and impatience. Journal of Labor Economics, $23,3,527-588$.

Diamond, P.A. (1965). The evaluation of infinite utility streams. Econometrica, 33, 170-177.

Diamond, P.A., Koopmans, T.C. \& Williamson, R. (1962). Axioms for persistent preference. In R.E. Machol \& P. Gray (Eds.), Recent developments in information and decision processes. New York: Macmillan.

Donahue, J.D. \& Zeckhauser, R.J. (2011). Collaborative governance: Private sector roles for public goals in turbulent times. Princeton, NJ: Princeton University Press.

Doyle, J.R. (2013). Survey of time preference, delay discounting models. Judgment and Decision Making, 8, 2, 116-135.

Duflo, E., Banerjee, A., Glennerster, R. \& Kothari, D. (2010). Improving immunization coverage in rural India: A clustered randomized controlled evaluation of immunization campaigns with and without incentives. British Medical Journal, 340, 2220.

Duflo, E., Kremer, M. \& Robinson, J. (2008). How high are rates of return to fertilizer? Evidence from field experiments in Kenya. American Economic Review, 98, 2, 482-488. 


\section{RAIS COLLECTIVE VOLUME - ECONOMIC SCIENCE}

Edgeworth, F.Y. (1881). Mathematical physics: An essay on the application of mathematics to the moral sciences. Kondon: Kegan. Retrieved from https://archive.org/details/mathematicalpsy01goog

Ebert, J.E. \& Prelec, D. (2007). The fragility of time: Time-insensitivity and valuation of the near and far future. Management Science, 53, 9, 1423-1438.

Edwards, W. (1954). The theory of decision making. Psychological Bulletin, 51, 380-417.

Edwards, W. (1961). Behavioral decision theory. Annual Review of Psychology, 12, 473-498.

Epper, T., Fehr-Duda, H. \& Bruhin, A. (2011). Viewing the future through a warped lens: Why uncertainty generates hyperbolic discounting. Journal of Risk and Uncertainty, 43, 169-203.

Estle, S.J., Green, L., Myerson, J. \& Holt, D.D. (2007). Discounting of money and directly consumable rewards. Psychological Science, 18, 58-63.

Etzioni, A. (2012). The privacy merchants: What is to be done? The Journal of Constitutional Law, 14, 4, 929-951.

Evans, A.M. \& Krueger, J.I. (2009). The psychology and economics of trust. Social and Personality Psychology Compass, 3, 6, 1003-1017.

Feldstein, M.S. (1965). The derivation of social time preference rates. Kyklos, 18, 277-287.

Fishburn, P.C. (1966). Stationary value mechanisms and expected utility theory. Journal of Mathematical Psychology, 3, 434-457.

Fishburn, P.C. (1968). Utility theory. Management Science, 14, 5, 335-378.

Flaherty, D. (1989). Protecting privacy in surveillance societies: The federal republic of Germany, Sweden, France, Canada, and the United States. Chapel Hill, NC: The University of North Carolina Press.

Fowler, R., Hodge, B., Kress, G. \& Trew, T. (1979). Language and control. London: Routledge.

Frederick, S., Loewenstein, G. \& O’Donoghue, T. (2002). Time discounting and time preference: A critical review. Journal of Economics Literature, 40, 351-401.

Gaudeul, A. \& Giannetti, C. (2017). The effect of privacy concerns and social network formation. Journal of Economic Behavior \& Organization, 141, 233-253.

Gentner, D. (2002). The psychology of mental models. In N.J. Smelser \& P.B. Bates (Eds.), International Encyclopedia of the Social and Behavioral Sciences, pp. 9683-9687. Amsterdam: Elsevier.

Gigerenzer, G. (2014). Risk savvy: How to make good decisions. New York, NY: Viking.

Gigerenzer, G. (2016). Towards a rational theory of heuristics. In R. Frantz \& L. Marsh (Eds.), Minds, Models and Milieux: Commemorating the Centennial of the Birth of Herbert Simon. Basingstoke, UK: Palgrave Macmillan.

Green, L., Fry, A.F. \& Myerson, J. (1994). Discounting of delayed rewards: A life-span comparison. Psychological Science, 5, 33-36.

Green, L. \& Myerson, J. (2004). A discounting framework for choice with delayed and probabilistic rewards. Psychological Bulletin, 130, 769-792.

Greenberg, A. \& Collins, S. (1966). Paired comparison taste tests: Some food for thought. Journal of Marketing Research, 3, 76-80.

Hansen, A. (2006). Do declining discount rates lead to time inconsistent economic advice? Ecological Economics, 60, 138-144. 
Harrison, G.W., Lau, M I, \& Williams, M.B. (2002). Estimating individual discount rates in Denmark: A field experiment. American Economic Review, 92, 5, 1606-1617.

Henderson, N. \& Bateman, I. (1995). Empirical and public choice evidence for hyperbolic social discounting rates and the implications for intergenerational discounting. Environmental and Resource Economics, 5, 413-423.

Heyman, G.M. (1996). Resolving the contradictions of addiction. Behavioral and Brain Sciences, 19, 591-610.

Hoch, St. \& Loewenstein, G. (1991). Time-inconsistent preferences and consumer self-control. Journal of Consumer Research, 17, 492-507.

Horberg, E.J., Oveis, C. \& Keltner, D. (2011). Emotions as moral amplifiers: An appraisal tendency approach to the influences of distinct emotions upon moral judgments. Emotion Review, 3, 237244.

Hornsby, J. (2007). An empirical investigation of the effects of discounting on privacy related decisions. Dissertation: Nova Southeastern University.

Horowitz, J.K. \& Carson, R.T. (1990). Discounting statistical lives. Journal of Risk and Uncertainty, 3, 4, 403-413.

Jevons, W.St. (1871). The theory of political economy. London: Macmillan. Retrieved from http://www.econlib.org/library/YPDBooks/Jevons/jvnPECover.html

Johnson, D. (2009). Ethical theory and business. Upper Saddle River, NJ: Pearson Prentice Hall.

Kahneman, D. (2011). Thinking, fast and slow. New York: Farrar, Straus and Giroux.

Kahneman, D., Slovic, P. \& Tversky, A. (1982). Judgment under uncertainty: Heuristic and biases. New York: Cambridge University Press.

Kahneman, D. \& Thaler, R. (1991). Economic analysis and the psychology of utility: Applications to compensation policy. American Economic Review, 81, 341-346.

Kahneman, D. \& Tversky, A. (1979). Prospect theory: An analysis of decision under risk. Econometrica, 47, 2, 263-291.

Kahneman, D. \& Tversky, A. (2000). Choices, values, and frames. Cambridge, MA: Cambridge University Press.

Keeler, E.G. \& Cretin, S. (1983). Discounting of life-saving and other non-monetary effects. Management Science, 29, 300-306.

Keller, L.R. \& Strazzera, E. (2002). Examining predictive accuracy among discounting models. Journal of Risk and Uncertainty, 24, 2 143-160.

Kirby, K.N. (1997). Bidding on the future: Evidence against normative discounting of delayed rewards. Journal of Experimental Psychology: General, 126, 54-70.

Kirby, K.N. \& Herrnstein, R.J. (1995). Preference reversals due to myopic discounting of delayed reward. Psychological Science, 6, 2, 83-89.

Kirby, K.N. \& Marakovic, N.N. (1995). Modeling myopic decisions: Evidence for hyperbolic delaydiscounting within subjects and amounts. Organizational Behavior \& Human Decision Processes, 64, 22-30.

Klein, B. \& Meckling, W. (1958). Application of operations research to development decisions. Operations Research, 6, 352-363.

Koopmans, T.C. (1960). Stationary ordinary utility and impatience. Econometrica, 28, 287-309. 


\section{RAIS COLLECTIVE VOLUME - ECONOMIC SCIENCE}

Koopmans, T.C. (1964). On flexibility of future preferences. In M.W. Shelly and G.L. Bryan (Eds.), Human Judgments and Optimality. New York: Wiley.

Koopmans, T.C., Diamonds, P.A. \& Williamson, R.E. (1964). Stationary utility and time perspective. Econometrica, 32, 82-100.

Kosinski, M., Stillwell, D. \& Graepel, T. (2013). Private traits and attributes are predicable from digital records of human behavior. Proceedings of the National Academy of Sciences, 110, 15, 5802-5805.

Kosinski, M., Bachrach, Y., Stillwell, D.J., Kohli, P. \& Graepel, T. (in press). Manifestations of user personality in website choice and behavior on online social networks. Machine Learning Journal.

Laibson, D. (1997). Golden eggs and hyperbolic discounting. Quarterly Journal of Economics, 11, 443-477.

Laibson, D., Repetto, A. \& Tobacman, J. (2003). A debt puzzle. In P. Aghion, R. Frydman, J. Stiglitz, and M. Woodford, (Eds.), Knowledge, Information, and Expectations in Modern Economics: In Honor of Edmund S. Phelps, pp 228-266. Princeton: Princeton University Press.

Laux, F.L. \& Peck, R.M. (2007). Economic perspectives on addiction: Hyperbolic discounting and internalities. Social Science Research Network working paper retrieved November 3, 2015 at http://papers.ssrn.com/sol3/papers.cfm?abstract_id=1077613

Lerner, J.S., Small, D.A. \& Loewenstein, G. (2004). Heart strings and purse strings: Carryover effects of emotions on economic transactions. Psychological Science, 15, 5, 337-341.

Lessig, L. (2006). Code: Version 2.0. New York, NY: Basic.

Luce, R.D. \& Suppes, P. (1965). Preference, utility, and subjective probability. In R.D.. Luce, R.R., Bush and E. Galanter (Eds.), Handbook of mathematical psychology, pp. 103-189, New York: Wiley.

Loewenstein, G. (1992). The fall and rise of psychological explanations in the economics of intertemporal choice. In G. Loewenstein \& J. Elster (Eds.), Choice over time, pp. 3-34, New York: Sage.

Loewenstein, G. \& Prelec, D (1993). Preferences for sequences of outcomes. Psychological Review, 100, 91-108.

Luce, R.D. \& Raiffa, H. (1957). Games and decisions: Introduction and critical survey. New York: Dover.

Madden, G.L., Bickel, W.K. \& Jacobs, E.A. (1999). Discounting of delayed rewards in opioiddependent outpatients: Exponential or hyperbolic discounting functions? Experimental and Clinical Psychopharmacology, 7, 3, 284-293.

Majumdar, T. (1958). The measurement of utility. London: Macmillan.

Marschak, J. (1950). Rational behavior, uncertain prospects, and measurable utility. Econometrica, 18, 111-141.

Marglin, S.A. (1963). The social rate of discount and the optimal rate of investment. Quarterly Journal of Economics, 77, 95-111.

Marquardt, R., Makens, J. \& Larzelere, H. (1965). Measuring the utility added by branding and grading. Journal of Marketing Research, 2, 45-50.

Marx, K. (1867/1995). Capital: A critique of political economy. Moscow: Progress. 
Mas-Colell, A., Whinston, M.D. \& Green, J.R. (1995). Microeconomic theory. New York: Oxford University Press.

Mastrobuoni, G. \& Weinberg, M. (2009). Heterogeneity in intra-monthly consumption patterns, selfcontrol, and savings at retirement. American Economic Journal: Economic Policy, 1, 2, $163-$ 189.

Mazur, J. E. (1987). An adjusting procedure for studying delayed reinforcement. In M.M. Commons, J.A. Nevvin and H. Rachlin (Eds.), Quantitative Analyses of Behavior. Hillsdale, NJ: Lawrence Erlbaum.

McClure, S., Ericson, K., Laibson, D., Loewenstein, G. \& Cohen, J. (2007). Time discounting for primary rewards. Journal of Neuroscience, 27, 21, 5796-5804.

Meier, St. \& Sprenger, Ch. (2010). Stability of time preferences. IZA Discussion Paper 4756, Institute for the Study of Labor.

Meyer, A.G. (2009). Estimating individual level discount factors and testing competing discounting hypotheses. Dissertation: University of Colorado.

Meyer, A.G. (2013). Estimating discount factors for public and private goods and testing competing discounting hypotheses. Journal of Risk and Uncertainty, 46, 133-173.

Milkman, K.L., Rogers, T. \& Bazerman, M.H. (2008). Harnessing our inner angels and demons: What we have learned about want/should conflicts and how that knowledge can help us reduce shortsighted decision making. Perspectives on Psychological Science, 3, 4, 324-338.

Milkman, K.L., Rogers, T. \& Bazerman, M.H. (2009). Highbrow films gather dust: Time- inconsistent preferences and online DVD rentals. Management Science, 55, 6, 1047-1059.

Minsky, H.P. (1977). Banking and a fragile financial environment. The Journal of Portfolio Management, 3, 4, 16-22.

Moscovici, S. (1988). Notes towards a description of social representations. Journal of European Social Psychology, 18, 3, 211-250.

Murphy, J.G., Vuchinich, R.E. \& Simpson C.A. (2001). Delayed reward and cost discounting. Psychological Record, 51, 571-588.

Myerson, J. \& Green, L. (1995). Discounting of delayed rewards: Models of individual choice. Journal of Experimental Analysis of Behavior, 64, 263-276.

Okada, E.M. \& Hoch, S.J. (2004). Spending time versus spending money. Journal of Consumer Research, 31, 313-323.

Orwell, G. (1949). 1984. New York: Harcourt Brace.

Oster, S.M. \& Scott-Morton, F.M.S. (2005). Behavioral biases meet the market: The case of magazine subscription prices. Advances in Economic Analysis \& Policy, 5, 1, 1, 1-32.

Oulasvirta, A., Suomalainen, T., Hamari, J., Lampinen, A., Karvonen, K. (2014). Transparency of intentions decreases privacy concerns in ubiquitous surveillance. Cyberpsychology, Behavior, and Social Networking, 17, 10, 633-638.

Paluck, E.L. (2009). What's in a norm? Sources and processes of norm change. Journal of Personality and Social Psychology, 96, 594-600.

Pareto, V. (1906/2014). Manual of political economy. Oxford, UK: Oxford University Press.

Petry, N.M. \& Casarella, T. (1999). Excessive discounting of delayed rewards in substance abusers with gambling problems. Drug and Alcohol Dependence, 56, 1, 25-32. 


\section{RAIS COLLECTIVE VOLUME - ECONOMIC SCIENCE}

Posner, R.A. (1981). The economic of privacy. The American Economic Review, 71, 2, 405-409.

Puaschunder, J. M. (2015). On the social representations of intergenerational equity. Oxford Journal of Finance and Risk Perspectives, 4, 4, 78-99.

Puaschunder, J.M. (2016). Trust and reciprocity drive common goods allocation norms. Proceedings of the Cambridge Business \& Economics Conference. Cambridge, UK: Cambridge University. Proceedings of the 2015 6th International Conference of the Association of Global Management Studies at Alfred Lerner Hall of Columbia University, New York: The Association of Global Management Studies. (Forthcoming). Oxford Journal: An International Journal of Business \& Economics.

Puaschunder, J.M. (2017). Nudgital: Critique of Behavioral Political Economy. Archives of Business Research, 5, 9, 54-76.

Puaschunder, J.M. (work in progress). On the collective soul of booms and busts. Retrievable at https://papers.ssrn.com/sol3/papers.cfm?abstract_id=2799646

Puaschunder, J.M. \& Schwarz, G. (2012). The future is now: How joint decision making curbs hyperbolic discounting but blurs social responsibility in the intergenerational equity public policy domain. Harvard University Situationist Law and Mind Sciences Working Paper.

Putnam, H. (2002). On the rationality of preferences. In H. Putnam (Ed.), The Collapse of the FactValue Dichotomy and Other Essays. Cambridge, MA: Harvard University Press.

Rachlin, H., Raineri, A. \& Cross, D. (1991). Subjective probability and delay. Journal of the Experimental Analysis of Behavior, 55, 233-244.

Ramsey, F.P. (1928). A mathematical theory of savings. Economic Journal, 38, 543-559.

Read, D. (2001). Is time-discounting hyperbolic or subadditive? Journal of Risk and Uncertainty, 23, 1, 5-32.

Read, D., Frederick, S. \& Airoldi, M. (2012). Four days later in Cincinnati: Longitudinal tests of intertemporal preference reversals due to hyperbolic discounting. Acta Psychologica, 140, 2, 177-185.

Read, D., Loewenstein, G. \& Kalyanaraman, S. (1999). Mixing virtue and vice: The combined effects of hyperbolic discounting and diversification. Journal of Behavioral Decision Making, 12, 257273.

Read, D. \& van Leeuwen, B. (1998). Predicting hunger: The effects of appetite and delay on choice. Organizational Behavior and Human Decision Processes, 76, 2, 189-205.

Read, D.R. (1964). A quantitative approach to the comparative assessment of taste quality in the confectionery industry. Biometrics, 20, 143-155.

Reed, D.D. \& Martens, B.K. (2011). Temporal discounting predicts student responsiveness to exchange delays in a classroom token system. Journal of Applied Behavior Analysis, 44, 1-18.

Reuben, E., Sapienza, P. \& Zingales, L. (2010). Time-discounting for primary and monetary rewards. Economic Letters, 106, 2, 125-127.

Rothenberg, J. (1961). The measurement of social welfare. Englewood Cliffs, NJ: Prentice Hall.

Roberts, A. S. (2010). The logic of discipline: Global capitalism and the architecture of government. New York: Oxford University Press.

Salanié, F. \& Treich, N. (2005). Over-savings and hyperbolic discounting. European Economic Review, 50, 6, 1557-1570. 
Samuelson, P.A. (1937). A note on measurement of utility. The Review of Economic Studies, 4, 155161.

Schumpeter, J. A. (1949). Economic theory and entrepreneurial history. Cambridge, MA: Harvard University Press.

Shaikh, A. (2016). Capitalism: Competition, conflict, crises. Oxford: Oxford University Press.

Simon, H.A. (1957). Models of man: Social and rational. New York: Wiley.

Sen, A.K. (1971). Choice functions and revealed preference. The Review of Economic Studies, 38, 3, 307-317.

Sen, A.K. (1977). Rational fools: A critique of the behavioral foundations of economic theory. Philosophy and Public Affairs, 6, 4, 317-344.

Sen, A.K. (1993). Internal consistency of choice. Econometrica, 61, 3, 495-521.

Sen, A.K. (1995). Rationality and social choice. The American Economic Review, 85, 1, 1-24.

Sen, A.K. (1997). Maximization and the act of choice. Econometrica, 65, 4, 745-780.

Sen, A.K. (2002a). Consistency of choice. In A. Sen (Ed.), Rationality and Freedom. Cambridge, MA: Harvard University Press.

Sen, A.K. (2002b). Goals, commitment, and identity. In A. Sen (Ed.), Rationality and Freedom. Cambridge, MA: Harvard University Press.

Shackle, G.L.S. (1955). Uncertainty in economics and other reflections. Cambridge: Cambridge University Press.

Shah, A.K. \& Oppenheimer, D. (2008). Heuristics made easy: An effort-reduction framework. Psychological Bulletin, 134, 2, 207-222.

Shui, H. \& Ausubel, L.M. (2004). Time inconsistency in the credit card market. Social Science Research Network working paper retrieved October 25, 2015 at http://ssrn.com/abstract $=586622$

Shannon, C.E. (1948). A mathematical theory of communication. The Bell System Technical Journal, $27,379-423$.

Silberberg, S. (2000). The structure of economics: A mathematical analysis. Boston: McGraw-Hill.

Simon, H.A. (1979). Rational decision making in business organizations. American Economic Review, 69, 4, 493-513

Simon, H.A. \& Bartel, R.D. (1986). The failure of armchair economics. Challenge, 29, 5, 18-25.

Simon, H.A. (1959). Theories of decision making in economics and behavioral science. American Economic Review, 49, 253-283.

Slonim, R., Carlson, J. \& Bettinger, E. (2007). Possession and discounting behavior. Economic Letters, 97, 3, 215-221.

Solove, D.J. (2008). Understanding privacy. Cambridge, MA: Harvard University Press.

Stafford, J.E. (1966). Effects of group influences on consumer brand preferences. Journal of Marketing Research, 3, 68-75.

Sterner, T. (1994). Discounting in a world of limited growth. Environmental and Resource Economics, 4, 527-534.

Stillson, P. (1954). A method for defect evaluation. Industrial Quality Control, 11, 9-12.

Strotz, R.H. (1957). Myopia and inconsistency in dynamic utility maximization. Review of Economic Studies, 23, 165-180. 


\section{RAIS COLLECTIVE VOLUME - ECONOMIC SCIENCE}

Suppes, P. (1961). Behavioristic foundations of utility. Econometrica, 29, 186-202.

Suzuki, G. (1957). Procurement and allocation of naval electronic equipments. Naval Research Logistics Quarterly, 4, 1-7.

Thaler, R.H. (1981). Some empirical evidence on dynamic inconsistency. Economics Letters, 8, 3, 201-207.

Thaler, R.H. \& Shefrin, H.M. (1981). An economic theory of self-control. Journal of Political Economy, 89, 392-406.

Trope, Y. \& Fishbach, A. (2000). Counteractive self-control in overcoming temptation. Journal of Personality and Social Psychology, 79, 4, 493-506.

Thaler, R. H. \& Sunstein, C. R. (2008). Nudge. Improving decisions about health, wealth, and happiness. New Haven: Yale University Press.

van der Pol, M. \& Cairns, J. (2001). Estimating time preferences for health using discrete choice experiments. Social Science and Medicine, 52, 9, 1459-1470.

von Neumann, J. \& Morgenstern, O. (1953). Theory of games and economic behavior. Princeton, NJ: Princeton University Press.

Wagner W., Lorenzi-Cioldi, F., Mankova, I. \& Rose, D. (1999). Theory and method of social representations. Asian Journal of Social Psychology, 2, 1, 95-125.

Warner, J.T. \& Pleeter, S. (2007). The personal discount rate: Evidence from military downsizing programs. American Economic Review, 91, 1, 33-53.

Warren, S. \& Brandeis, L. (1890). The right to privacy. Harvard Law Review, 4, 193-220.

Wertenbroch, K. (1998). Consumption self-control by rationing purchase quantities of virtue and vice. Marketing Science, 17, 4, 317-337.

Wold, H. (1952). Ordinal preferences or cardinal utility? Econometrica, 20, 661-664.

Witzany, G. (2012). Biocommunication of fungi. Dordrecht: Springer.

Zauberman, G., Kim, B.K., Malkoc, S.A. \& Bettman, J.R. (2009). Discounting time and time discounting: Subjective time perception and intertemporal preferences. Journal of Marketing Research, 46, 8, 543-556. 